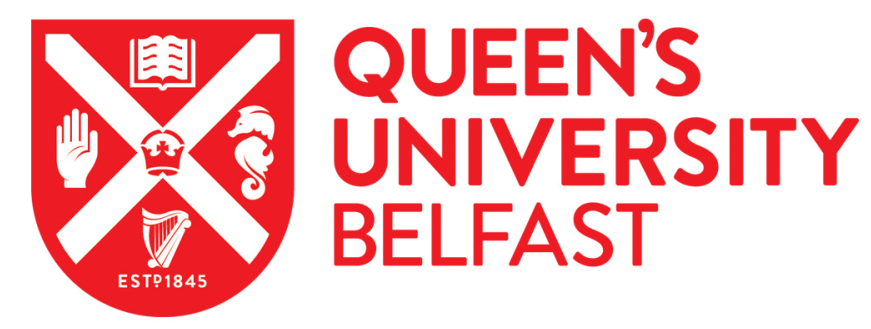

\title{
A Computational Toolchain for the Automatic Generation of Multiple Reduced-Order Models from CFD Simulations
}

Marzullo, T., Keane, M., Geron, M., \& Monaghan, R. F. D. (2019). A Computational Toolchain for the Automatic Generation of Multiple Reduced-Order Models from CFD Simulations. Energy, 180, 511-519.

https://doi.org/10.1016/j.energy.2019.05.094

\section{Published in:}

Energy

\section{Document Version:}

Peer reviewed version

\section{Queen's University Belfast - Research Portal:}

Link to publication record in Queen's University Belfast Research Portal

\section{Publisher rights}

Copyright 2019 Elsevier Ltd.

This manuscript is distributed under a Creative Commons Attribution-NonCommercial-NoDerivs License

(https://creativecommons.org/licenses/by-nc-nd/4.0/), which permits distribution and reproduction for non-commercial purposes, provided the author and source are cited.

\section{General rights}

Copyright for the publications made accessible via the Queen's University Belfast Research Portal is retained by the author(s) and / or other copyright owners and it is a condition of accessing these publications that users recognise and abide by the legal requirements associated with these rights.

Take down policy

The Research Portal is Queen's institutional repository that provides access to Queen's research output. Every effort has been made to ensure that content in the Research Portal does not infringe any person's rights, or applicable UK laws. If you discover content in the Research Portal that you believe breaches copyright or violates any law, please contact openaccess@qub.ac.uk. 
Elsevier Editorial System(tm) for Energy Manuscript Draft

Manuscript Number: EGY-D-18-07794R1

Title: A Computational Toolchain for the Automatic Generation of Multiple Reduced-Order Models from CFD Simulations

Article Type: VSI:SDEWES 2018

Keywords: CFD; ROM; buildings; zonal model; fluid network

Corresponding Author: Mr. Thibault Marzullo, M.Sc

Corresponding Author's Institution: National University of Ireland Galway

First Author: Thibault Marzullo, M.Sc

Order of Authors: Thibault Marzullo, M.Sc; Marcus M Keane, B.E., PhD; Marco Geron, PhD, M.Sc; Rory F Monaghan, PhD, M.Sc

Abstract: This paper describes the development of a systematic tool chain capable of automatically extracting accurate and efficient Reduced-Order Models (ROMs) from Computational Fluid Dynamics (CFD) simulations. These ROMs can then be used to support the design and operation of Near-Zero Energy Buildings (NZEB), with a higher accuracy than traditional zonal models but at a fraction of the computational cost of CFD. This study assesses the accuracy and time to solution of these ROMs when solved for appropriate Boundary Conditions (BCS), found in the built environment, in order to define the usability envelope of the automatically extracted ROMs. The parameters used in this study are inlet temperatures (K) and mass flow rates $(\mathrm{kg} / \mathrm{s})$. Results demonstrate that the absolute error can be maintained at under $0.5 \mathrm{~K}$ for changes in temperature of up to $\pm 15 \mathrm{~K}$, and under $0.25 \mathrm{~K}$ for changes in mass flow rates of up to $\pm 45 \%$ of the original value. The results show that this method has the potential for applications in the built environment where the ROM accuracy and low computational cost can bridge a gap between low order RC models and high order CFD, further improving the energy efficiency in smart buildings. 
November 28, 2018

\author{
Mr Thibault Marzullo, \\ Mechanical Engineering, \\ National University of Ireland Galway
}

Dear Editor in Chief,

We are submitting a manuscript "A Computational Tool-chain for the Automatic Generation of Multiple Reduced-Order Models from CFD Simulations” by T. Marzullo, M. Geron, M.M. Keane and R.F.D. Monaghan for publication in the special issue of Energy dedicated to SDEWES 2018. This sumbission follows the request from the conference organizers of an expanded version of SDEWES paper SDEWES2018.00388. It has not been published elsewhere or submitted simultaneously for publication elsewhere. We have no conflicts of interest to disclose.

The built environment accounts for $40 \%$ of global energy consumption, and smart buildings are being designed to minimize energy demand while maintaining occupant thermal comfort. In order to predict the impact of design choices on realistic indoor thermal conditions, accurate and fast computational tools are required. The manuscript presents a toolchain capable of automatically extracting a zonal reduced-order model (ROM) from a CFD simulation results, and examines the robustness of the ROM when it is subsequently solved for a different set of parameters associated with the domain of the built environment. The results demonstrate that the toolchain provides accurate and rapid results and does not require significant user expertise for the generation of the ROMs.

The toolchain improves the state-of-the-art in thermal modelling of the built environment firstly by providing an automatic tool, capable of generating a zonal model from CFD results. Currently most methods for the development of ROMs require user expertise, or need to be adapted to a specific case scenario. The presented toolchain enables users to generate ROMs with minimal input, reducing development costs and time considerably. Secondly, the zonal method presented in this study allows the generation of accurate ROMs that can be solved in real time. In fact, results show that temperature distributions are predicted with an error below the error of sensors commonly met in the built environment, for which ROMs have been solved in under $1 \mathrm{~s}$.

For these reasons, we believe that this manuscript is appropriate for publication in the SDEWES 2018 special issue of Energy, and if you feel that this manuscript is appropriate for this journal we suggest the following reviewers:

Dr. Adolfo Palombo, University Federico II of Naples (palombo@unina.it)

Dr. Annamaria Buonomano, University Federico II of Naples (annamaria.buonomano@unina.it)

Professor Jan Hensen, Technical university of Eindhoven. ( j.hensen@tue.nl)

Thank you for your consideration.

Yours sincerely,

Thibault Marzullo

Marco Geron

Marcus M. Keane

Rory F.D. Monaghan 


\section{Response to reviewers:}

Dear reviewers and editor, thank you for reviewing our manuscript. Your comments have been very helpful and have improved this manuscript. Please find below the details on how we addressed them. You may also refer to the highlighted and tracked version of the revised manuscript.

\section{Reviewer \#1:}

- The analysis of the state of the art should be improved; the available literature shows numbers of nodal models, suitably developed for building simulation. It is useful for the reader to get the real goal of the work and which is the real contribution of the use of ROM from CFD in the building simulation field.

Sections 1.1 through 1.3 have been changed:

o in Section 1.1, each reference now has a short description of the method and the domain of application

- In Section 1.1, an explanation on the advantage of the presented method over zonal methods is presented

- In Section 1.2, removed redundant references

- In Section 1.3, removed redundant references and expanded the description of each method and their domains of application

- How the tools works is clearly reported at the Methodology session. It is not clear if massive elements are lumped in multiple nodes or not. Please, provide some info.

- In Section 2.2, last paragraph has been modified to clarify the structure of the fluid network model

- In Section 2.4, clarified how elements are each lumped in a separate node

- The whole analysis has been reported for a single Zone (office space); could you please provide info about its geometry and dimension?

- Section 2.1 has been expanded to provide more information on the office space.

- Simulation are provided for different temperatures and mass flow rates. Which is the simulation time in case of ROMs compared to CFDs?

- Section 3 expanded to include PC specifications and CFD simulation time.

- Fig. 5: the WMAE in case of MultiROM is quite high compared to CFD for T+5b, $T+5, T+10$ and $T+15$ cases. Would you discuss this outcome and justify it?

- Section 3.1 has been expanded to include a detailed explanation on the asymmetry of the error when solving for lower BC temperatures versus higher temperatures 
- Why by changing the BC mass flow rates the WMAE performance is better versus the temperature variation case (fig 5 vs. Fig. 6)?

Section

- Section 3.1 has been expanded to include a detailed explanation for the higher error when changing mass flow rates

Figure 6 highlights how for high values of the mass flow rate $(+45 \%,+60 \%$, +100 ) the error is higher compared to the error evaluated for the cases in which the temperature is increased. This is consequence of two factors. The first factor is the same as that described for the previous comment, the zones are immutable once they have been generated for the MultiROM scenario. The second factor is a consequence of the algorithm, in which it currently creates clusters based only on temperatures. The algorithm is currently not capable to accommodate changes in flow shapes as is the case when an air jet has more penetration in the domain as a result of higher mass flow rate. The algorithm deals with changes in the mass flow rate firstly by creating a map of flow rates in and out of each node. This provides weighting factors for each mass exchange between nodes. Consequently the evaluated weighting factors are applied to the new mass flow rate input

- It could be interesting to see how the model perform by simulating a larger room, which is the typology commonly treated by means of CFD tools. Have you ever tried to verify the reliability of the proposed tool on larger zones? Could be useful to test the proposed tool on such zones, by carrying out a parametric analysis or not?

We agree and have two plans underway to assess this lack.

1) We have replicated a validated CFD case of a naturally ventilated meeting room. It is double in size compared to the case presented in this manuscript, and the validation process included measurements of thermal comfort that will prove useful when testing CFD-ROM's capabilities in typical applications of BEMS.

So far, the CFD-ROM method performs similarly to the case presented in this manuscript. We regret that a proper validation of the case cannot be achieved before the revision deadline.

2) We have started discussions with researchers who develop CFD for the built environment in the hope that a collaboration might provide us with more case studies. We are looking for CFD simulations of large classrooms, sports complexes (swimming pools, gyms), and atriums as a first step.

- Finally, highlights are too long (the third one) and are not sufficiently focused on the paper content. Please, improve them (by adding more lines). We have updated the highlights as follows:

A method for extracting zonal models from CFD simulations is presented

A reduced fluid network model is generated by clustering CFD cells

The ROM can be solved for different boundary conditions

The model retains a high level of accuracy and is solved in real time

Reviewer \#2: 
- I suggest to develop this computer program with a further case study.

Since reviewer \#1 made a similar suggestion, allow us to copy our response here: We agree and have two plans underway to assess this lack.

1) We have replicated a validated CFD case of a naturally ventilated meeting room. It is double in size compared to the case presented in this manuscript, and the validation process included measurements of thermal comfort that will prove useful when testing CFD-ROM's capabilities in typical applications of BEMS.

So far, the CFD-ROM method performs similarly to the case presented in this manuscript. We regret that a proper validation of the case cannot be achieved before the revision deadline.

2) We have started discussions with researchers who develop CFD for the built environment in the hope that a collaboration might provide us with more case studies. We are looking for CFD simulations of large classrooms, sports complexes (swimming pools, gyms), and atriums as a first step.

\section{Editor:}

- Avoid lumping references as in [1, 2] and all other. Instead summarize the main contribution of each referenced paper in a separate sentence.

Sections 1.1 through 1.3 have been changed:

0 in Section 1.1, each reference now has a short description of the method and the domain of application

- In Section 1.1, an explanation on the advantage of the presented method over zonal methods is presented

- In Section 1.2, removed redundant references

- In Section 1.3, removed redundant references and expanded the description of each method and their domains of application 
Highlights

- A method for extracting zonal models from CFD simulations is presented

- A reduced fluid network model is generated by clustering CFD cells

- The ROM can be solved for different boundary conditions

- The model retains a high level of accuracy and is solved in real time 


\section{A Computational Toolchain for the Automatic Generation of Multiple Reduced-Order Models from CFD Simulations}

Thibault Marzullo*

DepartmentSchool of Mechanical-Engineering, National University of Ireland Galway,

University RoadGalway, Ireland

Ryan Institute, Galway, Ireland

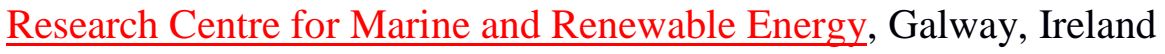

E-mail: t.marzullo1@nuigalway.ie

Marcus M. Keane

ĐepartmentSchool of Eivil-Engineering, National University of Ireland Galway, University RoadGalway, Ireland

$\underline{\text { Ryan Institute, Galway, Ireland }}$

Research Centre for Marine and Renewable Energy, Galway, Ireland

E-mail: marcus.keane@nuigalway.ie

Marco Geron

School of Mechanical and Aerospace Engineering

Queen's University Belfast, University Road,-Belfast, United Kingdom

E-mail: $\underline{\text { m.geron@qub.ac.uk }}$

Rory F.D. Monaghan

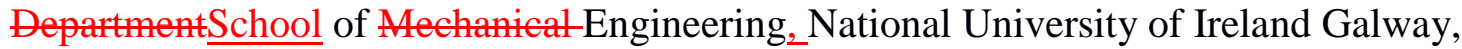

University RoadGalway, Ireland

Ryan Institute, Galway, Ireland

Research Centre for Marine and Renewable Energy, Galway, Ireland

E-mail: rory.monaghan@ nuigalway.ie 


\begin{abstract}
This paper describes the development of a systematic tool chain capable of automatically extracting accurate and efficient Reduced-Order Models (ROMs) from Computational Fluid Dynamics (CFD) simulations. These ROMs can then be used to support the design and operation of Near-Zero Energy Buildings (NZEB), with a higher accuracy than traditional zonal models but at a fraction of the computational cost of CFD. This study assesses the accuracy and time to solution of these ROMs when solved for appropriate Boundary Conditions (BCs), found in the built environment, in order to define the usability envelope of the automatically extracted ROMs. The parameters used in this study are inlet temperatures (K) and mass flow rates $(\mathrm{kg} / \mathrm{s})$. Results demonstrate that the absolute error can be maintained at under $0.5 \mathrm{~K}$ for changes in temperature of up to $\pm 15 \mathrm{~K}$, and under $0.25 \mathrm{~K}$ for changes in mass flow rates of up to $\pm 45 \%$ of the original value. The results show that this method has the potential for applications in the built environment where the ROM accuracy and low computational cost can bridge a gap between low order RC models and high order CFD, further improving the energy efficiency in smart buildings.
\end{abstract}

\title{
Keywords
}

CFD; ROM; buildings; zonal model 


\begin{tabular}{|c|c|}
\hline Abbreviatic & \\
\hline $\mathrm{BC}$ & Boundary Condition \\
\hline BEMS & Building Energy Management System \\
\hline CFD & Computational Fluid Dynamics \\
\hline CFD-ROM & Computational Fluid Dynamics - Reduced Order Model \\
\hline MultiCFD & ROM extracted and solved for the same BCs \\
\hline MultiROM & ROM extracted and solved for different $B C s$ \\
\hline NZEB & Near Zero Energy Buildings \\
\hline RANS & Reynolds Average Navier-Stokes \\
\hline RNG & Re-Normalisation Group \\
\hline ROM & Reduced Order Model \\
\hline WMAE & Weighted Mean Absolute Error (in K) \\
\hline
\end{tabular}

\section{Introduction}

In the recent and ever growing global motivation for the development of the sustainable production and usage of energy, buildings are being adapted with varying degrees of "smartness". Construction materials, urban planning, architecture and systems management are being carefully optimized, as designers develop or retrofit an increasing number of buildings to render them Near Zero Energy Buildings (NZEB) in accordance with the EU Energy Performance Building Directive 2010/31/EU. With the advent of modern computing it is common to simulate parts or the entirety of a building in order to make informed design choices. In addition, smart buildings can benefit from the information gathered and processed by Building Energy Management Systems (BEMS) during their operational phase.

These systems rely not only on the accuracy of the data gathered through sensors, but also on the accuracy of computer models needed to predict a response to a certain change in energy inputs. Ideally, these models should be extremely accurate. In reality, the computational requirements of such models can become so important as to render them completely impractical. Models are therefore simplified and guided by required accuracy of the results in the intended target application domain.

\subsection{Models used in building energy simulations}

When rapid solutions are needed, domains are usually simplified as nodal models. Such models assume that entire portions of a building can be approximated by a single uniform space, or a node. This allows designers to evaluate energy consumptions by running a large number of simulations, which is the case when yearly consumption estimates are needed or when the building stock of entire districts [1] [3] or towns [4] must be simulated. Nodat models can be expanded to become Multi-Nodal models, which allow an estimation of energy exchanges within a building [5] [8] and provide a better representation of energy consumptions. This allows designers to evaluate energy consumption by running a large number of simulations, which is the case when yearly consumption estimates are needed or when the building stock of entire districts for load forecasting [1] or demand side management [2], but also towns [3] must be simulated. A review from Allegrini et al. (2015) [4] focuses on district level modelling. Nodal models can be expanded to become multi-nodal models, which allow estimation of energy exchanges within a building and provide a better representation of energy consumptions. These models are often based on electrical circuit analogy such as presented in [5] and [6] and are used for example for estimating energy consumption [7] or thermal comfort [8] in buildings. 
For a more accurate description of thermal exchanges within a room or a building, zonal models are used. They subdivide a spacezone such as a room into several subzones and can be used to simulate effects such as thermal stratification, air plumes above convectors or air jets at HVAC inlets [9].[9]. This type of approach is also useful when studying user thermal comfort, air mixing and indoor air quality, all of which can vary greatly within a single room, but also air mixing and indoor air quality.. Megri et al. [9][9] published a review on zonal models and their applications. Zonal models usually rely on user expertise for the definition of each subzone. The number of sub-zones, their location in the domain and the properties of each are defined manually by the modeller, making it a time-consuming and error-prone process.

\subsection{CFD applications in the built environment}

For studying flow patterns more closely, designers have access to Computational Fluid Dynamics (CFD) modelling technologies. The CFD modelling technique subdivides a numerical domain into many smaller finite volumes, usually hundreds of thousands to millions of computational cells. By computing partial differential Navier-Stokes, mass and energy balance equations between each cell and over the entire numerical domain, CFD simulations can provide an accurate description of flow magnitude and direction, thermal exchanges, distributions of temperature, pressure, density, and other properties.

The main drawbacks of CFD are high computational cost and the extensive user expertise needed to accurately model the boundary conditions, which have an important impact on the final results.

CFD simulations are used to assess indoor air quality and pollutant dispersion [10] [12], thermal comfort [13] [15], and are extensively used in studies relating to naturally ventilated buildings [10], [16] [21]. CFD is also often used when simulating urban environments, in which researchers studied the effects of urban heat islands [22] [24], wind profiles in streets and around buildings [17], [25] [29], pollutant dispersion [30] [40], and the impact of vegetation on cities' living environment [31], [38].

\subsection{CFD-model-order reduction}

In an effort to leverage CFD's aceuracy at a fraction of the computational cost, researehers have developed techniques aimed at simplifying or extracting reduced order models (ROMs) from CFD simulations. The literature presents methods such as: the use of coarse grids to reduce the computational load [30] [32]; zero-equation models [33] where turbulence models are greatly simplified; Pressure Implicit with Splitting of Operator (PISO) [41] which is derived from the Semi-Implicit Method for Pressure Linked Equations (SIMPLE) algorithm [42]; semi Lagrangian PISO [43]; projection methods [44]; Proper Orthonormal Decompesition (POD) [45] and balanced POP [46], [47], in which a series of snapshots are used to characterize a complex system; balanced truncation [48], and Fast Fluid Dynamies (FFD) [49], [50].

CFD simulations are used to assess indoor air quality and pollutant dispersion [10], thermal comfort [11], and are extensively used in studies relating to naturally ventilated buildings such as in [12]. Etheridge (2015) presents CFD as a suitable method in a review on natural ventilation [13]. CFD is also often used when simulating urban environments, in which researchers studied the effects of urban heat islands [14], wind profiles in streets [15] and 
around buildings [16]. Like for indoor environments, CFD is used for studies on outdoor pollutant dispersion [17]. The impact of wind canyons and densely built environments on city breathability has been simulated with CFD in [18], and likewise the impact of vegetation as seen in [19].

\subsection{CFD model order reduction}

In an effort to leverage CFD's accuracy at a fraction of the computational cost, researchers have developed techniques aimed at simplifying or extracting reduced order models (ROMs) from CFD simulations. The literature presents methods such as the Pressure Implicit with Splitting of Operator (PISO) method [20] which is derived from the Semi-Implicit Method for Pressure-Linked Equations (SIMPLE) algorithm [21] and have been developed for noniterative computation of unsteady flows and later extended to steady-state, but it has important computational costs. This can be mitigated by using semi-Lagrangian PISO [22] which has a lower computational cost than PISO. Proper Orthonormal Decomposition (POD) [23] and balanced POD [24], are used to reduce a model's number of degrees of freedom when information on the flow pattern must be captured. Fast Fluid Dynamics (FFD) [25] is derived from projection methods [26] and allows real-time solution of Navier-Stokes equations and is typically applied to wind load calculations.

Generally, the development of these models is heavily dependent on the designer'smodeller's level of expertise. Each reduced order model is developed or requires adaptation to fit a specific domain problem, and therefore requires the input of an expert. It would be beneficial to have access to a systematic automated approach to facilitate model order reduction. This study proposes a method to leverage the results from an existing CFD simulation to automatically generate rapid and accurate zonal models without additional user expertise. These zonal models can then be used to simulate conditions for which no CFD simulation is available while retaining a high level of accuracy within a proposed domain.

\section{Methodology}

The proposed method for ROM generation automatically extracts a multi zonal model from a CFD simulation, which can then be solved for boundary condition parameters different from the original CFD. The main advantages of this method are the level of automation, which allows generation of ROMs with minimal user input and expertise; the level of fidelity compared to CFD, which enables the ROM to retain most of the CFD simulation's accuracy; and finally the computational cost, which allows the generation of ROMs in under 60 seconds and their solution in under 0.95 seconds.

The CFD-ROM method consists in 6 main steps as shown in Figure 1: (1) the results of a CFD simulation are imported, (2) CFD computational cells are clustered together to create zones, which are uniform volumes of air, (3) interactions between zones and between zones and domain boundaries are processed, (4) a ROM is generated and (5) solved, and finally (6) the solved ROM is remapped back to the CFD domain. 


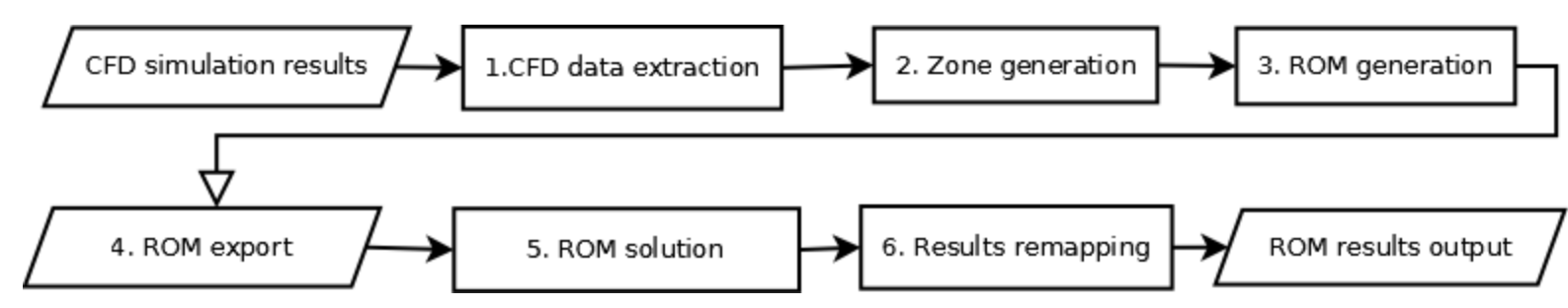

Figure 1: CFD-ROM method flowchart outlining the main steps of the method.

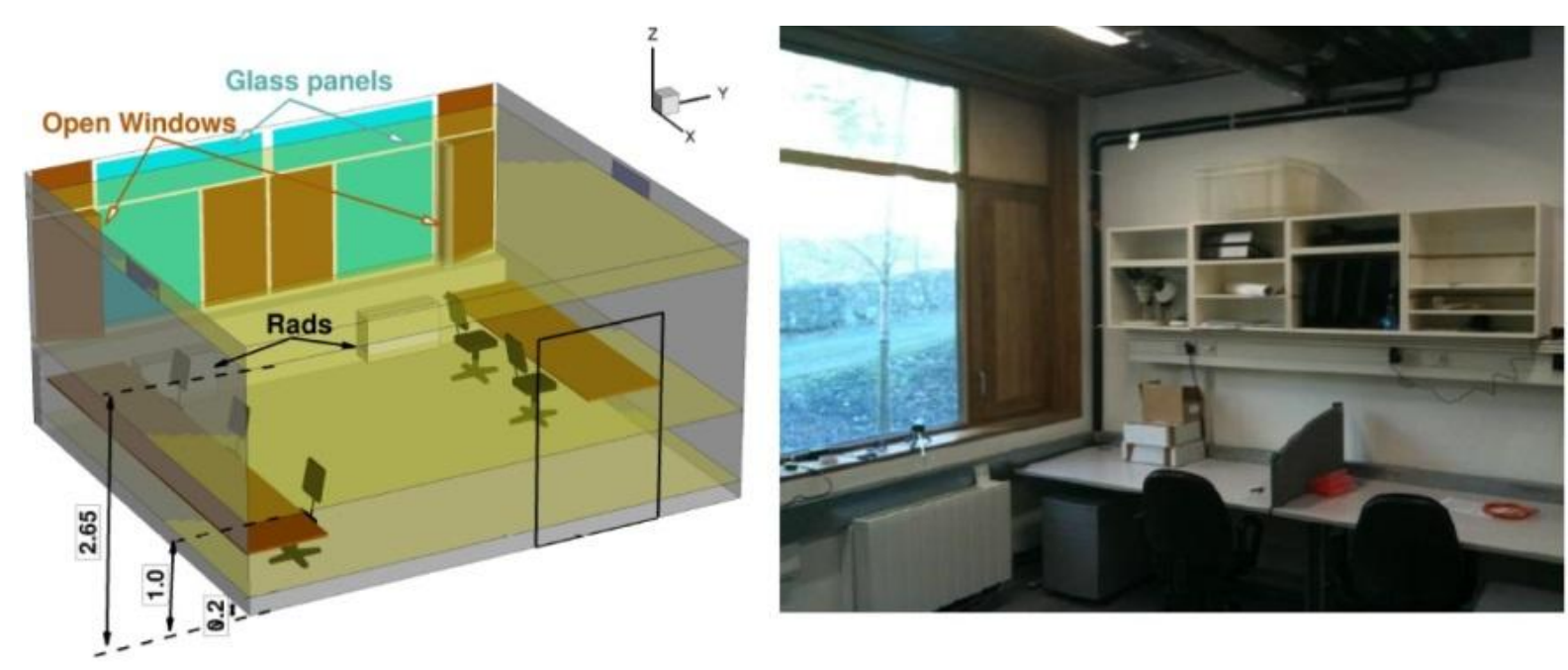

Figure 2: Numerical and physical domain of the ERI building office modelled in CFD

This section presents the methods used in the development of the algorithms in Python [51][27] for extraction and solution of the ROMs. Firstly, it presents the CFD simulations on which the ROMs have been tested and assessed, then the principles of zone generation, ROM generation and solution are explained.

\subsection{CFD Simulations and Validation}

The data used in this comparative study are taken from the previously-validated CFD model of a north-facing office in the Environmental Research Institute (ERI) building at University College Cork (UCC), shown in Figure 2 [52]. Steady state CFD models were developed using the Phoenies modelling software [53], which uses an immersed body technique. Therefore, a Cartesian structured grid was defined with $1,572,165$ cells $(115 \times 147 \times 93)$. Turbulence was modelled using the Reynolds Average Navier-Stokes (RANS) approach coupled with the ReNormalisation Group (RNG) $k$ \& turbulence model. Air was modelled as an incompressible ideal gas. The ceiling, floor, east and west walls were assumed to have a constant temperature. All other objects are considered adiabatic. All CFD simulations used have been validated with experimental data and previously published [52].

[28]. The office measures $5.2 \mathrm{~m}$ (length) by $5.6 \mathrm{~m}$ (width) by 2.9 (height). Its furniture includes five desks and chairs and shelf units. Two fan convectors heat the office and two automated windows are present. No other sources of heating, such as computers or people, are present. Steady state CFD models were developed using the Phoenics modelling software [29], which uses an immersed body technique. Therefore, a Cartesian structured grid was defined with 1,572,165 cells (115x147x93). Turbulence was modelled using the Reynolds Average Navier-Stokes (RANS) approach coupled with the Re-Normalisation Group (RNG) $k-\varepsilon$ turbulence model. Air was modelled as an incompressible ideal gas. The ceiling, floor, east 
and west walls were assumed to have a constant temperature. All other objects are considered adiabatic. All CFD simulations used have been validated with experimental data and previously published [28].

The CFD domain energy sources are listed in Table 1. In the case used for this study, the windows and door are closed and the two convectors are in an on state. The domain includes two air vents located on the east and west walls close to the ceiling. The two convectors are located on the north wall, close to the windows.

Table 1: CFD simulation base boundary conditions

\begin{tabular}{|c|c|c|c|}
\hline Boundary & Comment & Type & Base value \\
\hline \multicolumn{4}{|c|}{ Convectors } \\
\hline East convector & & Air inlet & $\begin{array}{l}\mathrm{T}_{\text {Econvector }}=45^{\circ} \mathrm{C} \\
\dot{\mathrm{m}}_{\text {Econvector }}=0.048 \mathrm{~kg} \cdot \mathrm{s}^{-1}\end{array}$ \\
\hline West convector & & Air inlet & $\begin{array}{l}\mathrm{T}_{\text {Wconvector }}=45^{\circ} \mathrm{C} \\
\dot{\mathrm{m}}_{\text {Wconvector }}=0.048 \mathrm{~kg} \cdot \mathrm{s}^{-1}\end{array}$ \\
\hline \multicolumn{4}{|c|}{ Walls } \\
\hline Ceiling & & Constant temperature & $\mathrm{T}_{\text {ceiling }}=23.2^{\circ} \mathrm{C}$ \\
\hline Floor & & Constant temperature & $\mathrm{T}_{\text {floor }}=18^{\circ} \mathrm{C}$ \\
\hline East wall & & Constant temperature & $\mathrm{T}_{\text {Ewall }}=20^{\circ} \mathrm{C}$ \\
\hline West wall & & Constant temperature & $\mathrm{T}_{\mathrm{Wwall}}=20^{\circ} \mathrm{C}$ \\
\hline \multicolumn{4}{|c|}{ Windows } \\
\hline East window & Closed & Air inlet & $\begin{array}{l}\mathrm{T}_{\text {Ewindow }}=9.35{ }^{\circ} \mathrm{C} \\
\dot{\mathrm{m}}_{\text {Ewindow }}=0 \mathrm{~kg} \cdot \mathrm{s}^{-1}\end{array}$ \\
\hline West window & Closed & Air inlet & $\begin{array}{l}\mathrm{T}_{\mathrm{W} \text { window }}=8.3{ }^{\circ} \mathrm{C} \\
\dot{\mathrm{m}}_{\text {Wwindow }}=0 \mathrm{~kg} \cdot \mathrm{s}^{-1}\end{array}$ \\
\hline \multicolumn{4}{|c|}{ Other openings } \\
\hline East vent & & Opening & $\begin{array}{l}\mathrm{T}_{\text {Event }}=20.2^{\circ} \mathrm{C} \\
\mathrm{P}_{\text {Event }}=1.013 \times 10^{5} \mathrm{~Pa}\end{array}$ \\
\hline West vent & & Opening & $\begin{array}{l}\mathrm{T}_{\text {Wvent }}=20.7^{\circ} \mathrm{C} \\
\mathrm{P}_{\text {Wvent }}=1.013 \times 10^{5} \mathrm{~Pa}\end{array}$ \\
\hline Door & Closed & & $\dot{\mathrm{m}}_{\text {door }}=0 \mathrm{~kg} \cdot \mathrm{s}^{-1}$ \\
\hline
\end{tabular}

\subsection{Zone Generation}

As stated previously, ROMs are created by clustering computational cells of the CFD domain, together depending on their position and their zone criterion. Zone criteria include any variable for which clustering is demanded, including for example temperature, density and air velocity. The method currently uses one criterion at a time, and the ROMs presented in this study have been generated with cell temperature as the zone criterion.

Firstly, zone-types are defined. A zone-type is a group of cells associated with a particular zone criterion over a specific interval, for example, temperatures. Such intervals are defined as follows: first the mean value of the temperature is processed over the entire CFD domain. Two zone-types are then defined: a zone-type containing all the cells in which temperature is higher than the mean value, and another containing all the cells in which temperature is lower or equal to the mean value. Subsequently the zone-types are iteratively subdivided into smaller zone-types, according to the mean value of temperature within each zone-type.

As a result, $2^{n}$ zone-types are defined, with $n$ the number of times this process is repeated. The user has control over the number of zone-types as this affects the discretization process. More 
zone-types allow a higher fidelity to the original CFD, but higher computational costs incur as discussed in the Results section.

Once zone-types have been defined for the ROM, the algorithm starts assigning cells to zones as shown in Figure 3. A zone is a cluster of computational cells which (1) are adjacent and (2) belong to the same zone-type. The algorithm starts by creating an empty zone and populates it with the first computational cell it finds.

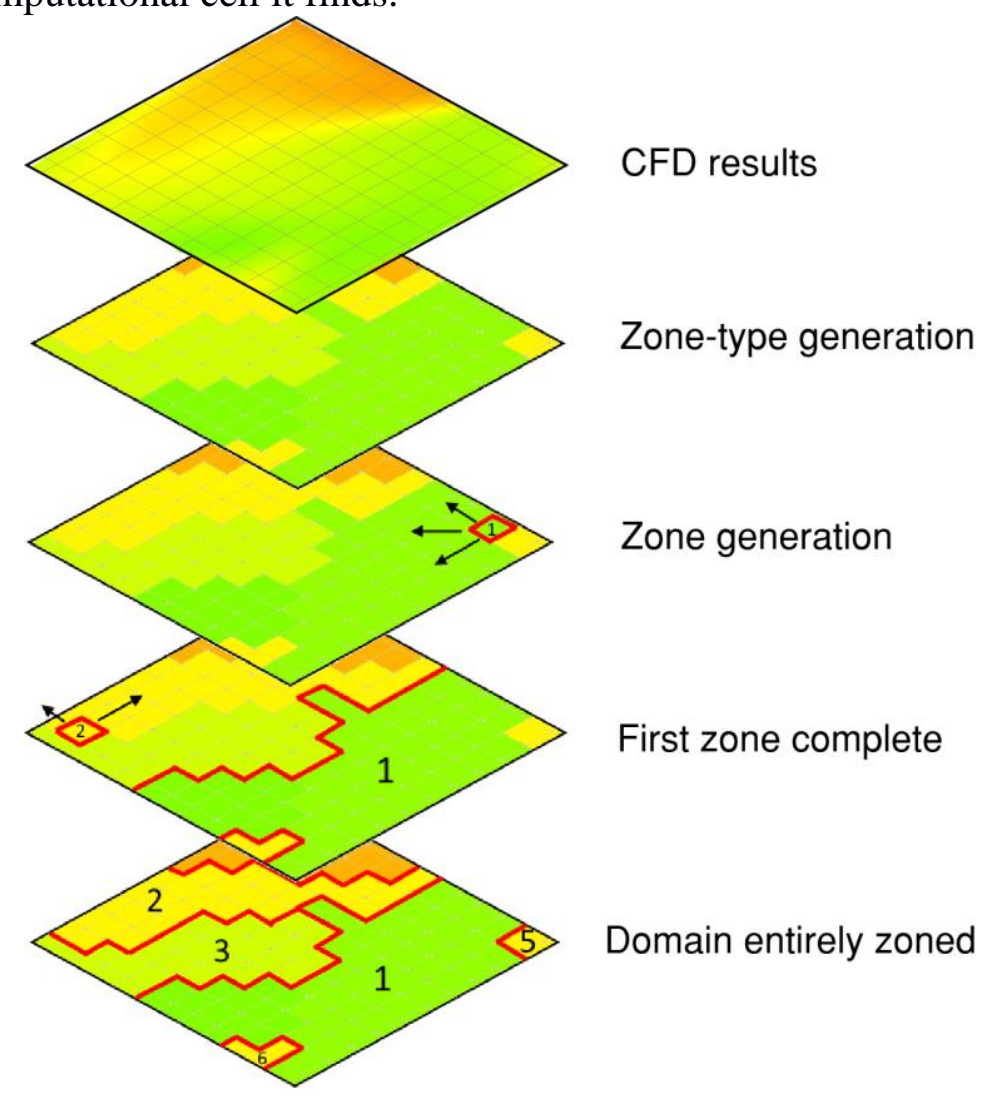

Figure 3: Representation of the zone generation algorithm in 2 dimensions. The algorithm first defines zone-types and then assigns all adjacent cells of the same zone-type to a new zone.

The cells adjacent to this initial cell are scanned, and if they belong to the same zone-type they are added to the zone. The same process is repeated for all the cells in the same zone, until no more suitable cells are found. At that point the algorithm creates a new zone and repeats the process until all the cells of the domain are assigned to a zone. A previous study $[54]$ A previous study $[30]$ by the authors assessed the accuracy of various zone generation algorithms.

Computationally, at this point the original CFD domain has been discretized from the original large number of cells to the final reduced number of zones. Each zone is lumped into a node of the fluid network representing the domain. In order to generate a ROM, it is then necessary to process interactions between zonesfluid nodes, and between zonesfluid nodes and domain boundaries. $\underline{\text { boundary nodes. }}$

\subsection{ROM Generation}

The first step in the ROM generation is to consider zones as uniform volumes in the CFD domain. The average values of temperature, density, and pressure are computed over the cells belonging to each zone in order to obtain the uniform zone properties. 
Next, the zone-zone interactions must be computed. The algorithm calculates the mass flow rates at the zone-zone interfaces by selecting all cells that have a neighbour assigned to a different zone and computing the unitary mass flow rate at the interface between these two neighbouring cells. The total mass flow rate between zones is calculated as the sum of all the unitary mass flow rates at the zone-zone interface.

After computing the zone-zone interactions, the algorithm detects the sources of energy such as air inlets and non-adiabatic walls. In a similar fashion to zone-zone interactions, the mass flow rates of inlets/outlets into/from each zone are computed at their interface and the total mass flow rate between an inlet/outlet and a zone is the sum of all unitary mass flow rates. Finally, the thermal boundaries such as non-adiabatic walls are assumed uniform, they are assigned an average temperature and a constant UA depending on their contact area with each zone.

\subsection{ROM Solution}

The ROMs are solved with Sinda/FLUINT [55],[31], a commercial software for finitedifference lumped parameter fluid flow analysis of complex systems. The data generated from zone properties and interactions with the domain are compiled to respect Sinda/FLUINT's input format: (1) zones are translated into "tanks", which are lumps of constant volume and uniform properties (temperature, density, pressure); (2) inlets and outlets are translated into "plena", which are similar lumps but with infinite volume; and (3) walls and other purely thermal sources are each translated to a thermal nodesnode, with uniform temperature. $A \underline{A}$ thermal and fluid network is then created, linking these elements through corresponding interactions: mass exchange between fluid lumps, and heat exchange between fluid lumps and thermal nodes. Mass exchanges are computed directly from the mass flow rates at zone-zone interfaces found previously, and heat exchanges are computed from a constant UA defined between each zone and thermal boundary. Once the model is solved, Sinda/FLUINT returns the steady-state solution with properties for each lump which can then be mapped back to the original CFD domain for comparison.

\subsection{Error measurement}

The present study uses the weighted mean absolute error (WMAE) in units of Kelvin, shown in Equation 1. The weighting corresponds to the volume of each cell relative to the total volume of the domain, in order to account for non-uniform cell volumes, especially close to the boundaries where the CFD mesh is finer.

$$
W M A E=\sum_{i=0}^{n} \frac{V_{i} \times\left|T_{C F D i}-T_{i}\right|}{V_{\text {domain }}}
$$

Where $n$ is the number of cells in the domain, $V_{i}$ is the volume of cell $i, V_{\text {domain }}$ is the total volume of the domain, $T_{C F D i}$ is the original CFD temperature of cell $i$, and $T_{i}$ is the temperature assigned to the cell after solving the ROM.

\section{Results}

This study presents the results obtained when modifying the parameters of a ROM to predict temperature distributions for BCs that differ from the ones of the original CFD simulations.

In order to achieve this, a set of CFD simulations was generated. For the same computational domain, simulations were solved featuring different inlet temperatures and mass flow rates. Table 2 presents the sets of parameters for boundary conditions used in this study. The CFD 
simulations, CFD-ROM program and ROM solver have been run on the same desktop computer (Intel Core $17-4790,8 \mathrm{~GB}$ RAM). The cases range from $\mathrm{T}-10$ to $\mathrm{T}+15$ for temperature, including $\mathrm{T}+5 \mathrm{~b}$ where only the temperature of the west convector is modified leaving the east one to $45^{\circ} \mathrm{C}$ (the base temperature); and from $\mathrm{M}-45 \%$ to $\mathrm{M}+100 \%$ for mass flow rates at the convectors.

Table 2: list of boundary conditions parameters used in MultiROM and MultiCFD

\begin{tabular}{ccc}
\hline Variable & Cases & Values \\
\hline Temperature $\left(\mathrm{T}_{\text {convector }}\right)$ & $\mathrm{T}-10$ & $35^{\circ} \mathrm{C}$ \\
& $\mathrm{T}-5$ & $40^{\circ} \mathrm{C}$ \\
& Base & $45^{\circ} \mathrm{C}$ \\
& $\mathrm{T}+5 \mathrm{~b}$ & $50^{\circ} \mathrm{C}(\mathrm{West}) \& 45^{\circ} \mathrm{C}$ (East) \\
& $\mathrm{T}+5$ & $50^{\circ} \mathrm{C}$ \\
\hline Mass flow rates $\left(\dot{\mathrm{m}}_{\text {convectors }}\right)$ & $\mathrm{T}+10$ & $55^{\circ} \mathrm{C}$ \\
& $\mathrm{T}+15$ & $60^{\circ} \mathrm{C}$ \\
\hline $\mathrm{M}-45 \%$ & $0.0528 \mathrm{~kg} . \mathrm{s}^{-1}$ \\
& $\mathrm{M}-30 \%$ & $0.0672 \mathrm{~kg} . \mathrm{s}^{-1}$ \\
& $\mathrm{Base}$ & $0.096 \mathrm{~kg} . \mathrm{s}^{-1}$ \\
& $\mathrm{M}+30 \%$ & $0.1248 \mathrm{~kg} . \mathrm{s}^{-1}$ \\
& $\mathrm{M}+45 \%$ & $0.1392 \mathrm{~kg} . \mathrm{s}^{-1}$ \\
\hline $\mathrm{M}+60 \%$ & $0.1536 \mathrm{~kg} . \mathrm{s}^{-1}$ \\
\hline
\end{tabular}

ROMs have been generated for zone numbers ranging from 2 to 51 in order to define at which point the error converges. The error quickly decreases for 2-11 zones then stabilizes around 22 zones and is nearly constant thereafter, as shown in Figure 4, while the corresponding solution times vary from $0.9 \mathrm{~s}$ for 2 zones to $1.1 \mathrm{~s}$ for 51 zones-, against 6 to 7 hours for the CFD simulation. Therefore, the ROMs presented in this study are in the 20-25 zones range, due to the fact thatsince while the user can demand a certain number of zones, there are occasionally a limited number of odd zones created to accommodate large temperature

gradients in the domain. The error in this case is particularly low due to the fact thatbecause the extracted ROM is solved for the same BCs as the original CFD simulation, and as such it does not represent the intended use for the CFD-ROM method. The following section presents the results in the case of ROMs being solved for a different set of BCs and for which CFD results are not available, as would ideally be the case for the application of the CFD-ROM method. 


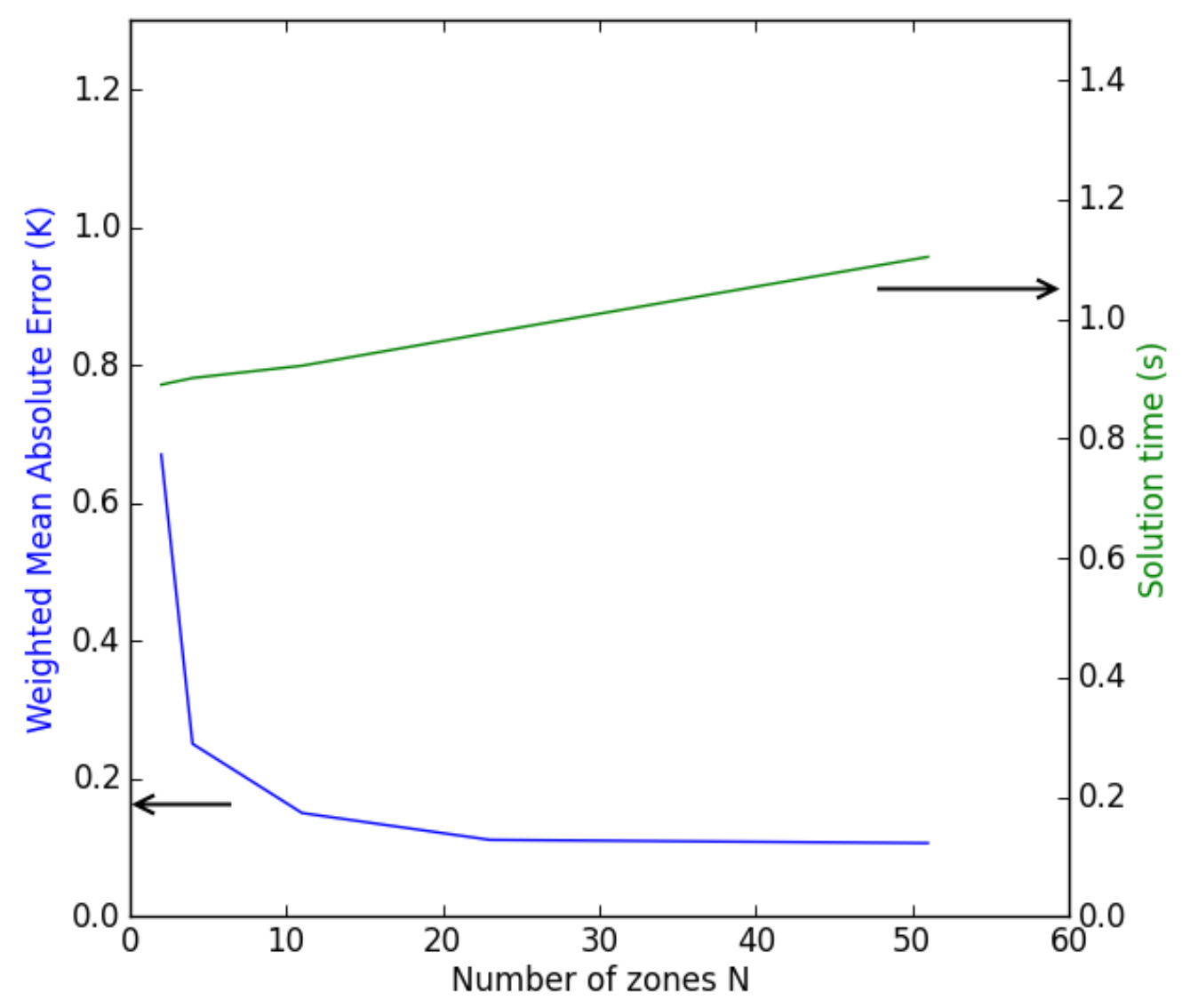

Figure 4: ROM size independence study.

\subsection{ROM accuracy when varying boundary condition parameters}

Two ROM case studies were generated to (i) measure the impact that changing the ROM parameters has on ROM accuracy, and (ii) assess the usability envelope of ROMs. The first, called "MultiCFD", uses a ROM generated directly from the corresponding CFD case. It serves as a basis for estimating the relative accuracy of the second case study, called "MultiROM", in which a ROM is generated from the base CFD case and subsequently solved with the new BC parameters. Developing a method for generating flexible and accurate MultiROMs is the main objective of this research. The aim is to provide designers and operators with a tool that would allow them to simulate the built environment when multiple CFD simulations are either unavailable or impractical.

The modelled office and its corresponding CFD simulation featuresfeature two convectors for which a temperature and air velocity are defined. This study assesses the accuracy of ROMs

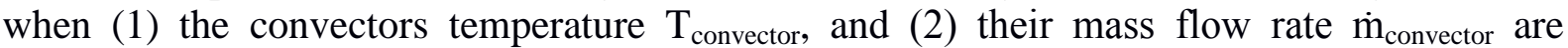
changed. The ROMs are extracted from the "base" CFD case, then their parameters are changed to match the other CFD cases, the ROMs are solved and finally their outputs are compared to the corresponding CFD case results.

The first test was to replicate previous results by the authors obtained when varying only temperatures by $\pm 5 \mathrm{~K}$ around the base temperature, then to reach $+15 \mathrm{~K}$ of variation around the base temperature. Figure 5 shows the absolute error for each case, in both MultiCFD and MultiROM scenarios. The ROMs show a good level of accuracy when solved for this range of parameters, considering the $\pm 0.6 \mathrm{~K}$ uncertainty range of temperature sensors commonly met in the built environment [56]. [32]. When the temperature is increased above the base 
temperature, the error is generally higher than ROMs solved for a temperature below the base temperature. This is a result of the immutability of the ROM's zones once they have been generated for the base case. The algorithm generates a fixed number of zones that cannot be changed after generation. In order to capture certain features, such as large temperature gradients, the algorithm will generate more zones around each feature. In the case of large temperature gradients, the number of zones depends on the amplitude of the gradient: the greater the gradient, the more zones are created. After generation of a ROM from the base case, when it is solved for lower temperatures the gradient is lower and the ROM therefore contains an excess of zones (from the base case) to characterize the smaller gradient, resulting in a smaller error. Conversely, when the ROM is solved for higher temperatures the preexisting number of zones is not sufficient to capture the larger temperature gradient, resulting in a larger error.

The second, and novel, set of results was generated by varying the convectors mass flow rates. In order to achieve this, an additional function was added to the code to ensure that the ROM mass flow rates were all balanced, as changing the inlets mass flow rates would alter the balance. This step is done in a purely mathematical manner, where zone by zone the inflows and outflows are iteratively balanced to match the new BCs. A connectivity table is generated by comparing the proportion of inflows and outflows from and to each zone and assigning weights to each, so that the general trend of mass exchange in the domain is respected in the modified ROM. The results are presented in Figure 6 and show that up to $\pm 45 \%$ of change in mass flow rates at the convectors, the ROM still has an absolute error under $0.5 \mathrm{~K}$ versus $0.11 \mathrm{~K}$ of error for the base, unmodified case - with the exception of the $+45 \%$ case with $0.84 \mathrm{~K}$ of absolute error. This again falls into the uncertainty range of common temperature sensors.

A similar trend exists of higher error for an increase in mass flow rates compared to a lower error for decreased mass flow rates when solving the ROM. This again is due to the immutability of zones once they have been generated, which cannot accommodate a change in flow shape.

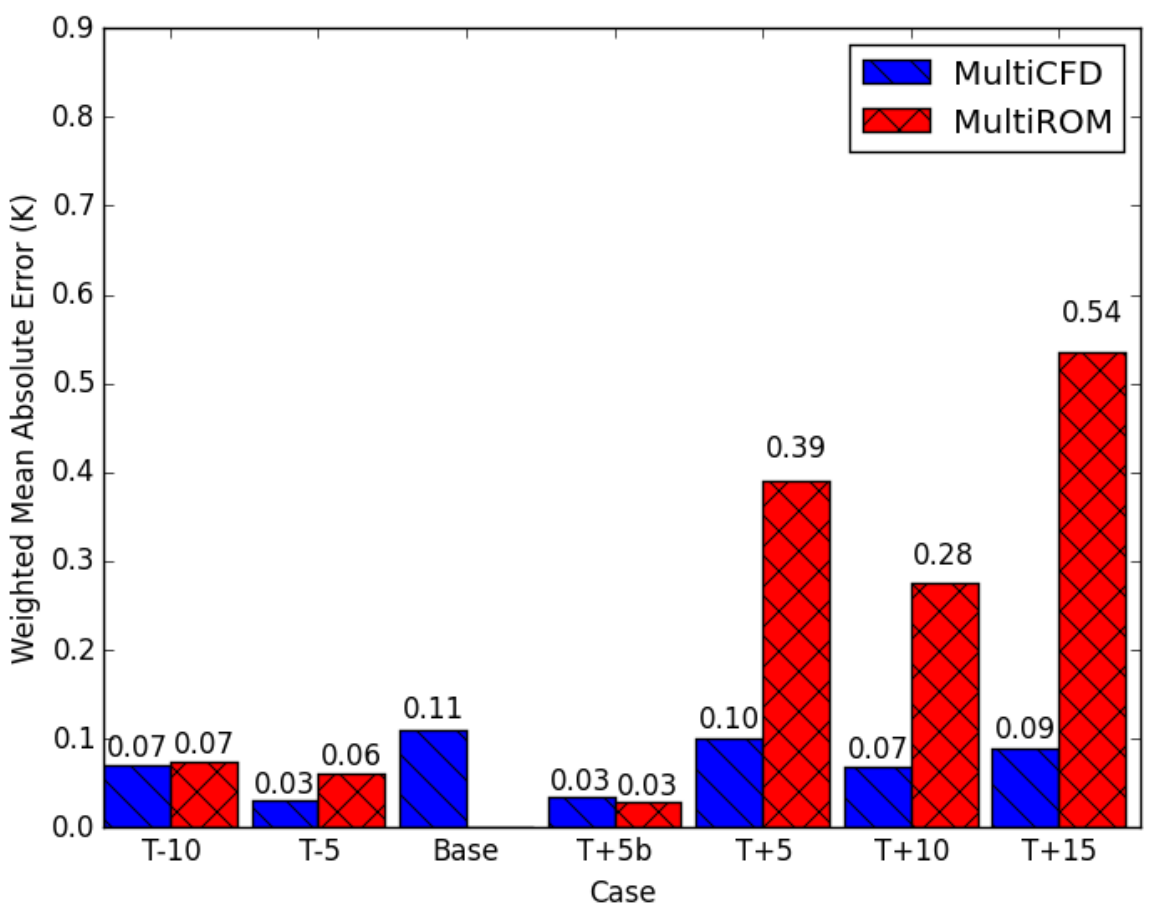

Figure 5: MultiCFD and MultiROM error when changing BC temperatures. 


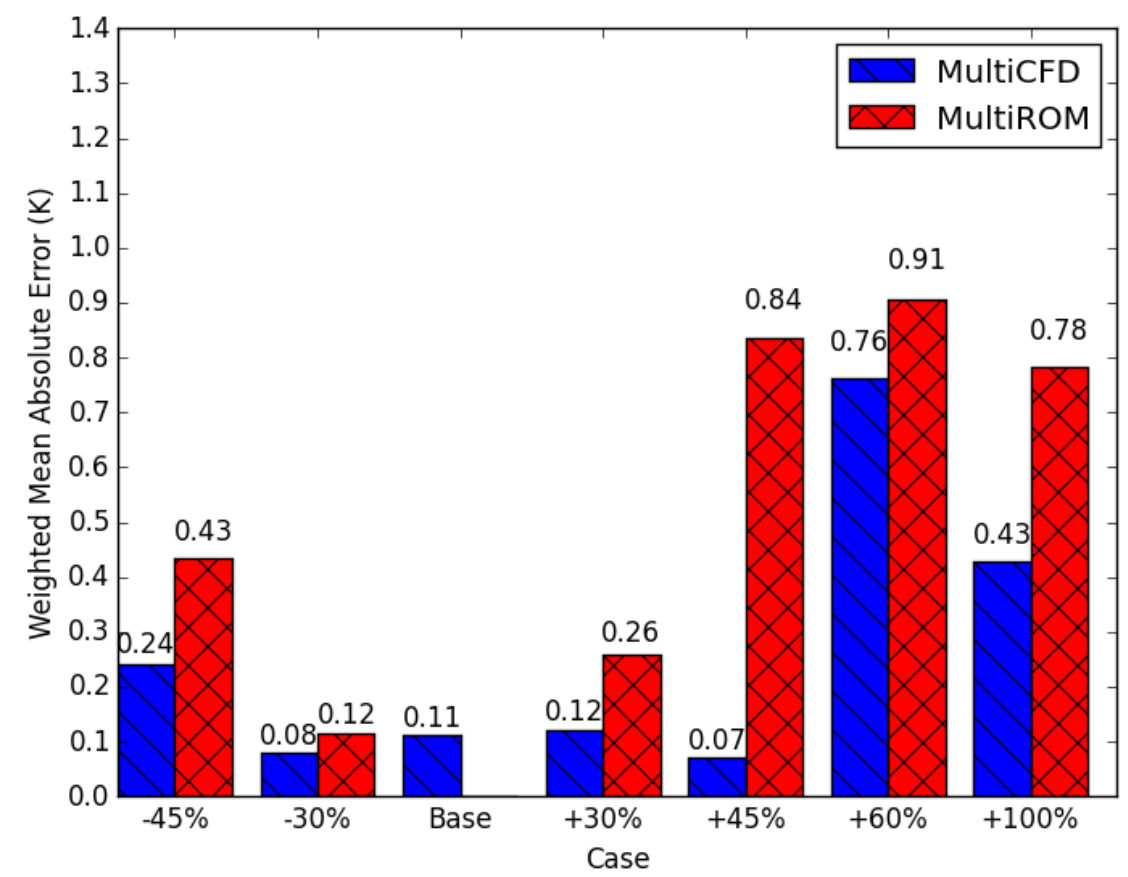

Figure 6: MultiCFD and MultiROM error when changing BC mass flow rates

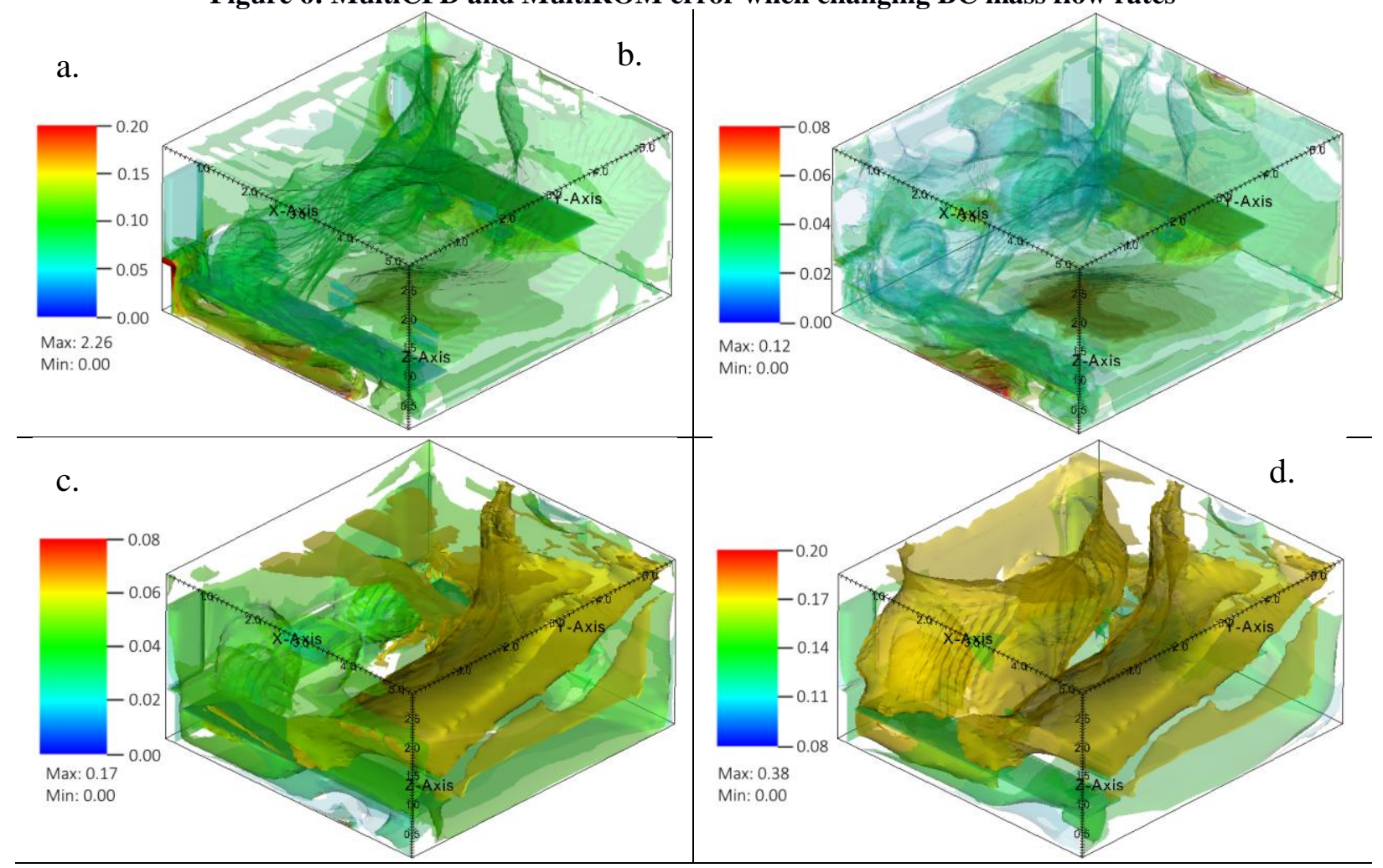

Figure 7: Iso-surface WMAE (in K) plots of cases (a) $\dot{\mathrm{m}}-\mathbf{4 5} \%$, (b) $\dot{\mathrm{m}}-\mathbf{3 0} \%$, (c) $\dot{\mathrm{m}}+\mathbf{3 0} \%$ and (d) $\dot{\mathrm{m}}+\mathbf{4 5 \%}$.

\subsection{Error plots}

A study of the local error was done in order to assess more finely the fidelity of the ROMs against the original CFD simulations. Figure 7 shows semi-opaque iso-surface plots of the m$45 \%$ to $\dot{\mathrm{m}}+45 \%$ cases. No peaks in local error stand out, except for a very limited number of odd cells due to minor computational errors. Such errors are due to a mechanism that prevents the algorithm from generating very small zones, which is necessary to avoid assigning too 
many zones to areas with large temperature gradients. These small zones would not be representative of the flow pattern, but their presence lowers the overall accuracy of the ROM as less zones are available for zoning the remainder of the domain. Without this mechanism, the ROMs would be able to capture large temperature gradients very finely, but would be unable to capture stratification.

Results are identical for the $\mathrm{T}-10$ to $\mathrm{T}+15$ cases, suggesting that the algorithm is able to accurately capture the domain's thermal distribution, including the volumes with high temperature gradients such as above and around the convectors. Figure 8 shows a X-Z slice of the domain at the centre of the west convector; and shows how the CFD-ROM method captures both the heat plume above the convector and also temperature stratification in the room. The limited error visible around the heat plume shows that setting a lower limit to the size of zones does not adversely affect to a great extent the algorithm's ability to capture high temperature gradients, while allowing it to also capture smaller variations in temperature.
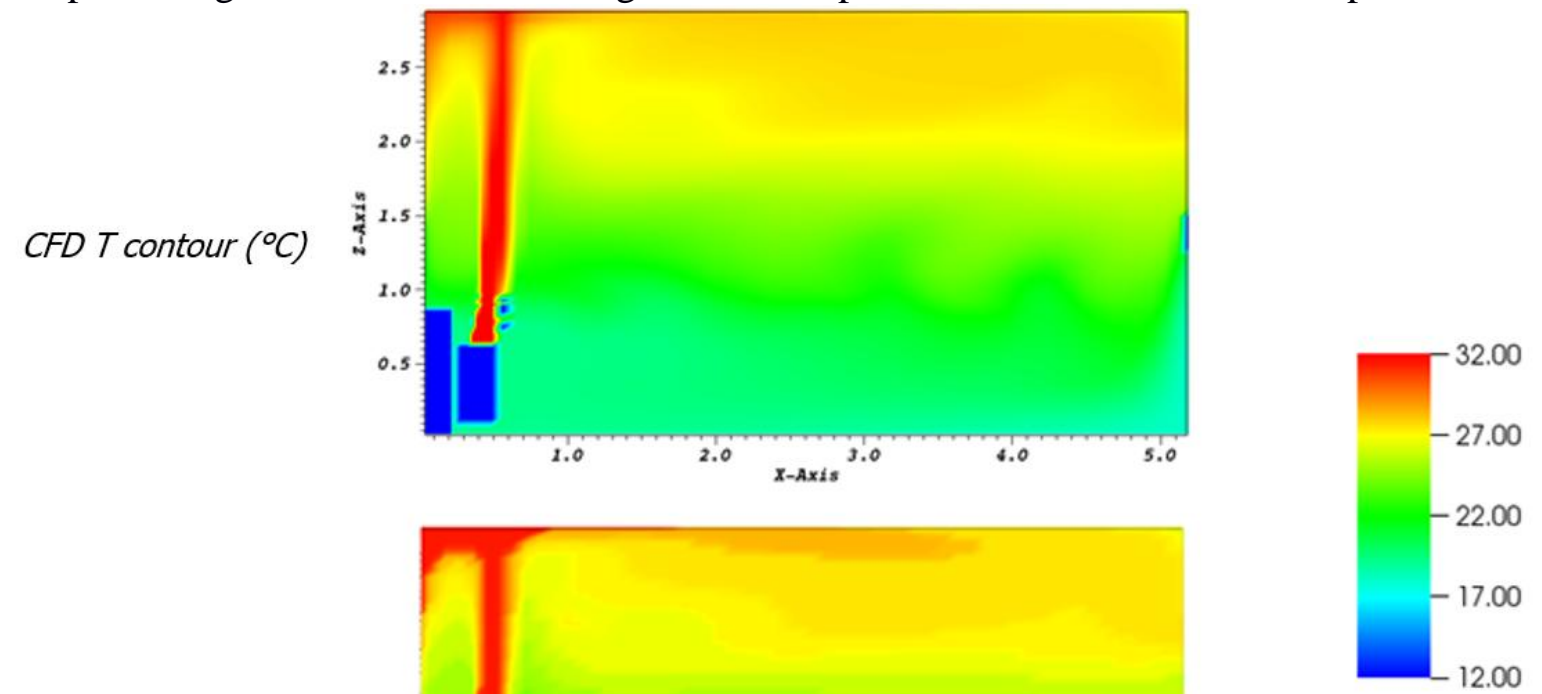

ROM T contour $\left({ }^{\circ} \mathrm{C}\right)$

Error (\%)
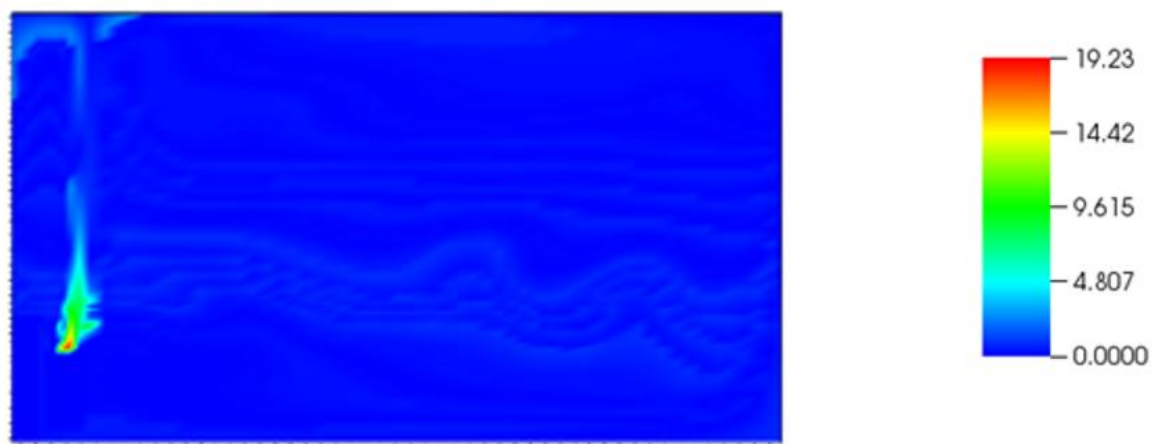

Figure 8: CFD temperature contour, ROM solution, and error plot of a X-Y slice at the centre of the west convector 


\section{Discussion}

This study showed that it is possible to extract multi-zonal ROMs from CFD simulations with high fidelity and in real time for application domains in the built environment. These findings can be mitigated by the relative simplicity of the case study utilised in this research, where only two convectors and two vents are present in the domain. Further research must be done on other indoor environments, such as open-space offices, theatre rooms or sports complexes in order to assess the usability of the method in more complex environments featuring larger spaces and openings, air vents, HVAC outlets, which could affect the accuracy of the ROMs.

Furthermore, it is currently up to the end user to select an appropriate number of zones for the ROM. An extreme example would be the selection of a 20-zone ROM in a domain with 19 air inlets: the algorithm would use 19 of the available zones to capture the air inlets, and only one to capture the rest of the domain. In order to generate a more appropriate number of zones it might be beneficial to set an upper limit to the size of each zone, so that the algorithm could if needed increase the number of zones without user input. There is a certain room for expansion in the number of zones, as this study has shown that the difference in time to solution between 3 and 50 zones is not significant and 20-25 zones are enough to model the presented case, yet further research must be done on complex scenarios to certify the usability of this method for larger numbers of zones.

In both studies, when varying temperature and mass flow rates the ROMs are generally more accurate when lowering the parameters values than they are when the values are increased. When solving for different BCs, the parameters computed on the base case are not valid any moreanymore and lead to increasing error as the new ROM differs more and more from the base case. This is likely caused by the immutability of zones after they have been generated from the base case and the assumptions made when compiling the model for Sinda/FLUINT, namely the constant values assigned to zone-zone mass flow rates and wall heat transfers. An improvement upon the current iteration of the method will be the implementation of variable mass flow rates and heat transfers. The asymmetrical change in error, lower when temperatures are colder and mass flow rates weaker, may beis due byto the fact that the domain becomes more and more uniform as the energy flow in the domain is lower, in which case the ROM has more zones than necessary to compute the new temperature distributions. Increasing the number of zones globally lowers the error but the asymmetry is still present to some extent.

Nevertheless, the results are encouraging when considering the usual $\pm 0.6 \mathrm{~K}$ uncertainty of temperature sensing techniques in the built environment [56].[32]. The possibility to change boundary temperatures by $\pm 15 \mathrm{~K}$ and mass flow rates by $\pm 45 \%$ while maintaining an acceptable level of accuracy allows the consideration of, for example, thermal comfort and HVAC control as potential applications for which further research must be done.

Additionally, the authors consider the inclusion of multiple-criteria zone generation, versus the current single-criterion zone generation, as an important upgrade to the algorithm which may improve its accuracy especially when mass flow rates must be changed. 


\section{Conclusion}

The accuracy of CFD is recognized to have a potentially substantial impact on building energy consumption through methods such as virtual sensing [57].[33]. Unfortunately, the computational costs involved in solving a CFD model render it unpractical for real-time applications such as BEMS. This study proposed a method capable of extracting ROMs from CFD simulations and solving them in near real-time. First an ROM size independence study was conducted, showing that it can be achieved for 20 to 25 zones for the presented case. The accuracy of ROMs that were solved and assessed for (1) different temperature BCs and (2) different mass flow rates. It was shown that it was possible to obtain accurate results, in real time, for boundary conditions that were different from the original CFD BCs. These multizonal ROMs have an accuracy comparable to the uncertainty in sensing equipment used in the built environment, thus rendering them useful in applications such as virtual sensing. This enables the use of CFD-ROM for thermal comfort assessment, BEMS, and applications where the unavailability of real-time zonal models is detrimental.

However, it is necessary to apply this method to more complex scenarios in order to confirm its advantages in terms of rapidity and accuracy, and it is also necessary to include additional features such as multi-criteria zone generation and a radiation model. Currently the authors are studying CFD simulations of a highly glazed, naturally ventilated room to further improve the CFD-ROM method, and look forward to applying the method to larger, more complex cases.

The next steps in the development of the CFD-ROM toolchain are: (1) the generation of ROMs for different indoor environments, such as highly glazed, naturally ventilated rooms; (2) the investigation of techniques that would improve ROMs accuracy when solving for different inlet mass flow rates; (3) the inclusion of a radiation model; and (4) the development of a tailored solver in the open-source language Modelica [58].[34].

\section{Acknowledgements}

The authors wish to acknowledge the following funding. T. Marzullo is supported by a Scholarship from the College of Engineering and Informatics at NUI Galway and by HIT2GAP (EU/H2020 Grant Agreement No.: 680708).

\section{References}

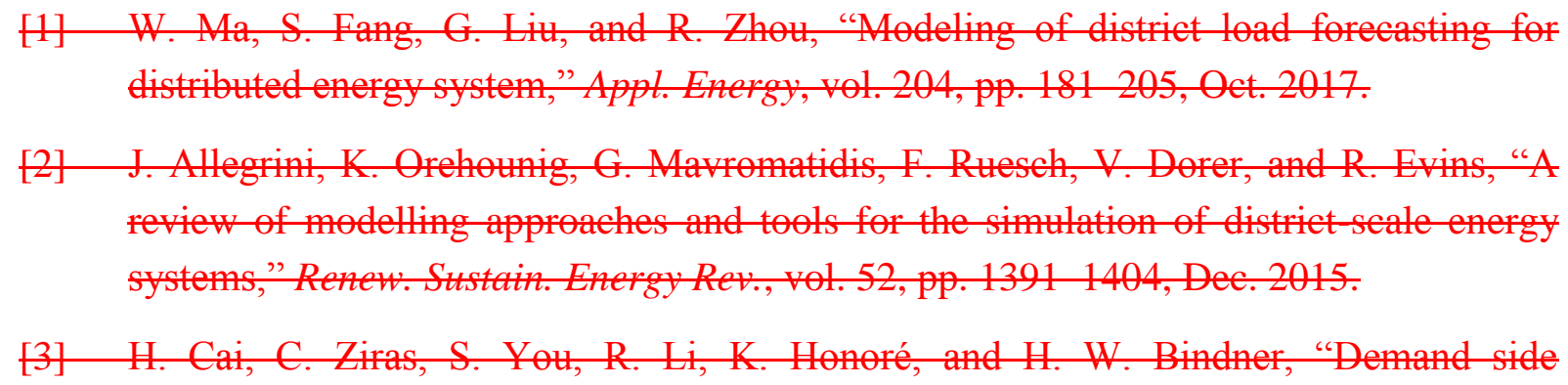
management in urban district heating networks," Appl. Energy, vol. 230, pp. 506 518, Nov. 2018. 
[4] P. Nageler, G. Schweiger, H. Schranzhofer, T. Mach, R. Heimrath, and C. Hochenauer, "Novel method to simulate large scale thermal city models", Energy, vol. 157, pp. 633 646, Aug. 2018.

[5] G. Fraisse, C. Viardot, O. Lafabrie, and G. Achard, "Development of a simplified and accurate building model based on electrical analogy," Energy Build., vol. 34, no. 10, pp. $1017-1031,2002$.

[6] V. S. K. V. Harish and A. Kumar, "Reduced order modeling and parameter identification of a building energy system model through an optimization routine," Appl. Energy, vol. 162, pp. 1010 1023, 2016.

[7] P. H. Shaikh, N. B. M. Nor, P. Nallagownden, I. Elamvazuthi, and T. Ibrahim, "A review on optimized control systems for building energy and comfort management of smart sustainable buildings," Renew. Sustain. Energy Rev., vol. 34, pp. 409-429, 2014.

[8] J. Hillary, E. Walsh, A. Shah, R. Zhou, and P. Walsh, "Guidelines for developing efficient thermal conduction and storage models within building energy simulations," Energy, vol. 125, pp. 211 222, Apr. 2017.

[9] A. C. Megri and F. Haghighat, "Zonal Modeling for Simulating Indoor Environment of Buildings: Review, Recent Developments, and Applications," HVAC\&R Res., vol. 13:6, pp. $887905,2007$.

[10] T. van Hooff and B. Blocken, "CFD evaluation of natural ventilation of indoor envirenments by the concentration decay method: $\mathrm{CO} 2$ gas dispersion from a-semienclosed stadium," Build. Enviren., vol.61, pp. 1 17, Mar. 2013.

[11] M. Bady, S. Kato, and H. Huang, "Towards the application of indoor ventilation efficiency indices to evaluate the air quality of urban areas," Build. Environ., vol. 43, no. 12, pp. 1991-2004, Dec. 2008.

[12] B. Blocken, Y. Tominaga, and T. Stathopoulos, "CFD simulation of micro-seale pollutant dispersion in the built environment," Build. Environ., vol. 64, pp. 225 230, Jun. 2013.

[13] C. Croitoru, I. Nastase, F. Bode, A. Meslem, and A. Dogeanu, "Thermal comfort models for indoor spaces and vehicles Current capabilities and future perspectives," Renew. Sustain. Energy Rev., vol. 44, pp. 304-318, 2015.

[14] X. Zhà, W. Liu, D. Lai, and Q. Chen, "Optimal design of an indoor environment by the CFD based adjoint method with area-constrained topology and cluster analysis," Build. Environ., vol. 138, pp. 171-180, Jun. 2018.

[15] N. Juseh, R. A. Bakar, A. R. Ismail, and T. Z. S. Ali, "Computational analysis of thermal building in a no uniform thermal environment," Energy Procedia, vol. 68, pp. 438 445, Apr. 2015. 
[16] G. Tan and L. R. Glicksman, "Application of integrating multi zone model with CFD simulation to natural ventilation prediction," Energy Build., vol. 37, no. 10, pp. 1049 1057, 2005.

[17] C. Yuan and E. Ng, "Practical application of CFD on environmentally sensitive architectural design at high density cities: A case study in Hong Kong," Urban Clim., vol. 8 , pp. $57-77,2014$.

[18] R. Ramponi and B. Blocken, "CFD simulation of cross-ventilation for a generie isolated building: Impact of computational parameters," Build. Enviren., vol. 53, pp. 34-48, Jul. 2012.

[19] F. Durrani, M. J. Cook, and J. J. McGuirk, "Evaluation of LES and RANS CFD modelling of multiple steady states in natural ventilation," Build. Environ., vol. 92, pp. $167181,2015$.

[20] D. Etheridge, " $A$ perspective on fifty years of natural ventilation research," Build. Enviren., vol. 91, pp. 51-60, Sep. 2015.

[21] B. Blocken, "50 years of Computational Wind Engineering: Past, present and future" J. Wind Eng. Ind. Aerodyn., vol. 129, pp. 69 102, Jun. 2014.

[22] A. Mochida and I. Y. F. Lun, "Prediction of wind environment and thermal comfort at pedestrian level in urban area," J. Wind Eng. Ind. Aerodyn., vol. 96, no. 10 11, pp. 1498 1527, Oet. 2008.

[23] B. Blocken, "Computational Fluid Dynamies for urban physies: Importance, seales, possibilities, limitations and ten tips and tricks towards accurate and reliable simulations," Build. Enviren., vol. 91, pp. 219-245, Feb. 2015.

[24] G. Maggiotte, R. Buccolieri, M. A. Sante, L. S. Lee, and S. Di Sabatine, "Validation of temperature perturbation and CFD based modelling for the prediction of the thermat urban environment: The Lecee (IT) case study," Environ. Model. Softw., vol. 60, pp. 69 83, 2014.

[25] B. Blocken and J. Perseon, "Pedestrian wind comfort around a large football stadium in an urban environment: CFD simulation, validation and application of the new Dutch wind nuisance standard," J. Wind Eng. Ind. Aerodyn., vol. 97, no. 5-6, pp. 255-270, Aug. 2009.

[26] B. Blocken, J. Carmeliet, and T. Stathopoulos, "CFD evaluation of wind speed eonditions in passages between parallel buildings effect of wall function roughness modifieations for the atmospheric boundary layer flow," J. Wind Eng. Ind. Aerodyn., vol. 95, no. 9-11, pp. 941-962, Oet. 2007.

[27] M. Skote, M. Sandberg, U. Westerberg, L. Claessen, and A. Johansson, "Numericat and experimental studies of wind environment in an urban morphology," Atmos. Enviren., vol. 39, no. 33, pp. 6147-6158, Oet. 2005. 
[28] Y. Tominaga et al., "AIJ guidelines for practical applications of CFD to pedestrian wind envirenment around buildings," J. Wind Eng. Ind. Aerodyn., vol. 96, no. 10 11, pp. 1749 1761, Oet. 2008.

[29] P. Moonen, V. Dorer, and J. Carmeliet, "Evaluation of the ventilation potential of courtyards and urban street canyons using RANS and LES," J. Wind Eng. Ind. Aerodyn., vol. 99, no. 4, pp. 414-423, Apr. 2011.

[30] J. Hang, Y. Li, M. Sandberg, R. Buccolieri, and S. Di Sabatino, "The influence of building height variability on pollutant dispersion and pedestrian ventilation in idealized high rise urban areas," Build. Environ., vol. 56, pp. 346 360, Oct. 2012.

[31] C. Gromke, R. Buccolieri, S. Di Sabatino, and B. Ruck, "Dispersion study in a street eanyon with tree planting by means of wind tunnel and numerical investigations Evaluation of CFD data with experimental data," Ammes. Enviren., vol. 42, no. 37, pp. $8640-8650$, Dec. 2008.

[32] S. M. Salim, S. C. Cheah, and A. Chan, "Numerical simulation of dispersion in urban street canyons with avenue-like tree plantings: Comparison between RANS and LES," Build. Enviren., vol.46, no. 9, pp. 1735 1746, Sep. 2011.

[33] X. Xie, Z. Huang, J. Wang, and Z. Xie, "The impact of solar radiation and street layout on pollutant dispersion in street canyon," Build. Enviren., vol. 40, no. 2, pp. 201 212, Feb. 2005 .

[34] Y. Tominaga and T. Stathopoulos, "CFD simulation of near field pollutant dispersion in the urban environment: A review of current modeling techniques," Atmos. Environ., ๒o1. 79, pp. 716 730, Nov. 2013.

[35] M. M. Hefny and R. Ooka, "CFD analysis of pollutant dispersion around buildings: Effect of cell geometry," Build. Enviren., vol.44, no. 8, pp. 1699-1706, Aug. 2009.

[36] G. Antonioni et al., "Comparison of CFD and operational dispersion models in an urban-like environment," Atmos. Environ., vol. 47, pp. 365 372, Feb. 2012.

[37] S. Di Sabatino, R. Buccolieri, B. Pulvirenti, and R. Britter, "Simulations of pollutant dispersion within idealised urban type geometries with CFD and integral models," Ames. Enviren., vol. 41, no. 37, pp. 8316 8329, Dec. 2007.

[38] R. Buccolieri, M. Sandberg, and S. Di Sabatine, "City breathability and its link to pollutant concentration distribution within urban like geometries," Atmos. Environ., vol. 44, no. 15, pp. 1894 1903, May 2010.

[39] M. Lateb, C. Masson, T. Stathopoulos, and C. Bédard, "Numerical simulation of pollutant dispersion around a building complex," Build. Environ., vol. 45, no. 8, pp. 1788-1798, Aug. 2010.

[40] P. Gousseau, B. Blocken, T. Stathopoulos, and G. J. F. van Heijst, "CFD simulation of near field pollutant dispersion on a high-resolution grid: A case study by LES and 
RANS for a building group in downtown Montreal," Atmos. Environ., vol. 45, no. 2, pp. 428-438, Jan. 2011.

[41] R. I. Issa, "Solution of the implicitly discretised fluid flow equations by operatorsplitting," J. Comput. Phys., vol. 62, no. 1, pp. 40-65, 1986.

[42] S. . Patankar and D. . Spalding, " $\Lambda$ calculation procedure for heat, mass and momentum transfer in three-dimensional parabolic flows," Int. J. Heat Mass Transf., vol. 15 , no. 10 , pp. 1787 1806, Oet. 1972.

[43] Y. Xue, W. Liu, and Z. (John) Zhai, "New semi-Lagrangian-based PISO method for fast and accurate indoor environment modeling," Build. Environ., vol. 105, pp. 236 $244,2016$.

[44] $\Lambda . J$. Chorin, " $\Lambda$ numerical method for solving incompressible viscous flow problems," J. Comput. Phys., vol. 2, no. 1, pp. 12 26, 1967.

[45] H. P. Bakewell, "Viscous Sublayer and Adjacent Wall Region in Turbulent Pipe Flow," Phys. Fluids, vol. 10, no. 9, p. 1880, 1967.

[46] K. E. Willcox and J. Peraire, "Balanced. . model reduction via the proper orthogonal decomposition." AIAA J, vol. 40, no. 11 SRC GeogleSchelar FG 0, pp. 23232330 , 2002 .

[47] C. W. Rowley, "Model Reduction for Fluids, Using Balanced Proper Orthogonat Decomposition," Int. J. Bifurc. Chaos, vol. 15, no. 3, pp. 997 1013, 2005.

[48] B. Moore, "Principal component analysis in linear systems: Controllability, observability, and model reduction," IEEE Trans. Automat. Contr., vol. 26, no. 1, pp. $1732,1981$.

[49] A. Robert, "A stable numerical integration scheme for the primitive meteorological equations," Atmosphere Ocean, vol. 19, no. 1, pp. 35-46, 1981.

[50] $\Lambda$. Staniforth and J. Côté, "Semi-Lagrangian Integration Schemes for Atmospherie Models A Review," Mon. Wea. Rev., vol. 119, no. 9, pp. 2206 2223, 1991.

[51] Python Software Foundation., "Python Language Reference, version 2.7."

[52] D. T. Mullen, M. M. Keane, M. Geren, and R. F. D. Monaghan, "Automatic extraction of reduced-order models from CFD simulations for building energy modelling," Energy Build., vol. 99, pp. 313 326, Jul. 2015.

[53] H. Rosten, D. Spalding, and D. Tatchell, "PHOENICS: a general purpose program for fluid flow, heat transfer and chemical reaction processes.," CHAM, 1983.

[54] T. Marzullo, S. Yousefian, M. M. Keane, M. Geron, and R. F. D. Monaghan, "A Comparative Study of Computational Algorithms used in the Automatic Generation of Reduced-Order Models from CFD Simulations," in 3rd Building Simulation Applications conference proceedings, 2017. 
[55] "SINDA/FLUINT." [Online]. Available: Www.crtech.com/sinda.html. [Accessed: 20 Jul 2016].

[56] H. Li, D. Yu, and J. E. Braun, "A Review of Virtual Sensing Technology and Application in Building Systems," HVAC\&R Res., vol. 9669, pp. 37-41, 2011.

[57] H. Tan and L. Dexter, "Improving the accuracy of sensors in building automation systems," in Proceedings of the 16th IFAC World Congress, 2005.

[58] P. Fritzson and V. Engelson, "Modelica A unified object oriented language for system modeling and simulation," ECOOP'98 Object Oriented Program., vol. 1445, pp. 67 90, 1998.

[1] W. Ma, S. Fang, G. Liu, and R. Zhou, "Modeling of district load forecasting for distributed energy system," Appl. Energy, vol. 204, pp. 181-205, Oct. 2017.

[2] H. Cai, C. Ziras, S. You, R. Li, K. Honoré, and H. W. Bindner, "Demand side management in urban district heating networks," Appl. Energy, vol. 230, pp. 506-518, Nov. 2018.

[3] P. Nageler, G. Schweiger, H. Schranzhofer, T. Mach, R. Heimrath, and C. Hochenauer, "Novel method to simulate large-scale thermal city models," Energy, vol. 157, pp. 633-646, Aug. 2018.

[4] J. Allegrini, K. Orehounig, G. Mavromatidis, F. Ruesch, V. Dorer, and R. Evins, "A review of modelling approaches and tools for the simulation of district-scale energy systems," Renew. Sustain. Energy Rev., vol. 52, pp. 1391-1404, Dec. 2015.

[5] G. Fraisse, C. Viardot, O. Lafabrie, and G. Achard, "Development of a simplified and accurate building model based on electrical analogy," Energy Build., vol. 34, no. 10, pp. $\underline{1017-1031,2002 .}$

[6] J. Hillary, E. Walsh, A. Shah, R. Zhou, and P. Walsh, "Guidelines for developing efficient thermal conduction and storage models within building energy simulations," Energy, vol. 125, pp. 211-222, Apr. 2017.

[7] V. S. K. V. Harish and A. Kumar, "Reduced order modeling and parameter identification of a building energy system model through an optimization routine," Appl. Energy, vol. 162, pp. 1010-1023, 2016.

[8] P. H. Shaikh, N. B. M. Nor, P. Nallagownden, I. Elamvazuthi, and T. Ibrahim, "A review on optimized control systems for building energy and comfort management of smart sustainable buildings," Renew. Sustain. Energy Rev., vol. 34, pp. 409-429, 2014.

[9] A. C. Megri and F. Haghighat, "Zonal Modeling for Simulating Indoor Environment of Buildings: Review, Recent Developments, and Applications," HVAC\&R Res., vol. 13:6, pp. 887-905, 2007.

[10] B. Blocken, Y. Tominaga, and T. Stathopoulos, "CFD simulation of micro-scale pollutant dispersion in the built environment," Build. Environ., vol. 64, pp. 225-230, Jun. 2013.

[11] X. Zhao, W. Liu, D. Lai, and Q. Chen, "Optimal design of an indoor environment by the CFD-based adjoint method with area-constrained topology and cluster analysis," Build. Environ., vol. 138, pp. 171-180, Jun. 2018. 
[12] T. van Hooff and B. Blocken, "CFD evaluation of natural ventilation of indoor environments by the concentration decay method: $\mathrm{CO} 2$ gas dispersion from a semienclosed stadium," Build. Environ., vol. 61, pp. 1-17, Mar. 2013.

[13] D. Etheridge, "A perspective on fifty years of natural ventilation research," Build. Environ., vol. 91, pp. 51-60, Sep. 2015.

[14] A. Mochida and I. Y. F. Lun, "Prediction of wind environment and thermal comfort at pedestrian level in urban area," J. Wind Eng. Ind. Aerodyn., vol. 96, no. 10-11, pp. 1498-1527, Oct. 2008.

[15] P. Moonen, V. Dorer, and J. Carmeliet, "Evaluation of the ventilation potential of courtyards and urban street canyons using RANS and LES," J. Wind Eng. Ind. Aerodyn., vol. 99, no. 4, pp. 414-423, Apr. 2011.

[16] B. Blocken and J. Persoon, "Pedestrian wind comfort around a large football stadium in an urban environment: CFD simulation, validation and application of the new Dutch wind nuisance standard," J. Wind Eng. Ind. Aerodyn., vol. 97, no. 5-6, pp. 255-270, Aug. 2009.

[17] J. Hang, Y. Li, M. Sandberg, R. Buccolieri, and S. Di Sabatino, "The influence of building height variability on pollutant dispersion and pedestrian ventilation in idealized high-rise urban areas," Build. Environ., vol. 56, pp. 346-360, Oct. 2012.

[18] R. Buccolieri, M. Sandberg, and S. Di Sabatino, "City breathability and its link to pollutant concentration distribution within urban-like geometries," Atmos. Environ., vol. 44, no. 15, pp. 1894-1903, May 2010.

[19] C. Gromke, R. Buccolieri, S. Di Sabatino, and B. Ruck, "Dispersion study in a street canyon with tree planting by means of wind tunnel and numerical investigations Evaluation of CFD data with experimental data," Atmos. Environ., vol. 42, no. 37, pp. 8640-8650, Dec. 2008.

[20] R. I. Issa, "Solution of the implicitly discretised fluid flow equations by operatorsplitting," J. Comput. Phys., vol. 62, no. 1, pp. 40-65, 1986.

[21] S. . Patankar and D. . Spalding, "A calculation procedure for heat, mass and momentum transfer in three-dimensional parabolic flows," Int. J. Heat Mass Transf., vol. 15, no. 10, pp. 1787-1806, Oct. 1972.

[22] Y. Xue, W. Liu, and Z. (John) Zhai, "New semi-Lagrangian-based PISO method for fast and accurate indoor environment modeling," Build. Environ., vol. 105, pp. 236244, 2016.

[23] H. P. Bakewell, "Viscous Sublayer and Adjacent Wall Region in Turbulent Pipe Flow," Phys. Fluids, vol. 10, no. 9, p. 1880, 1967.

[24] K. E. Willcox and J. Peraire, "Balanced model reduction via the proper orthogonal decomposition.," AIAA J, vol. 40, no. 11 SRC-GoogleScholar FG-0, pp. 2323-2330, 2002.

[25] A. Robert, "A stable numerical integration scheme for the primitive meteorological equations," Atmosphere-Ocean, vol. 19, no. 1, pp. 35-46, 1981.

[26] A. J. Chorin, "A numerical method for solving incompressible viscous flow problems," J. Comput. Phys., vol. 2, no. 1, pp. 12-26, 1967.

[27] Python Software Foundation., "Python Language Reference, version 2.7." .

[28] D. T. Mullen, M. M. Keane, M. Geron, and R. F. D. Monaghan, "Automatic extraction of reduced-order models from CFD simulations for building energy modelling," Energy Build., vol. 99, pp. 313-326, Jul. 2015.

[29] H. Rosten, D. Spalding, and D. Tatchell, "PHOENICS: a general-purpose program for fluid-flow, heat transfer and chemical-reaction processes.," CHAM, 1983.

[30] T. Marzullo, S. Yousefian, M. M. Keane, M. Geron, and R. F. D. Monaghan, "A Comparative Study of Computational Algorithms used in the Automatic Generation of 
Reduced-Order Models from CFD Simulations," in 3rd Building Simulation Applications conference proceedings, 2017.

[31] "SINDA/FLUINT." [Online]. Available: www.crtech.com/sinda.html. [Accessed: 20Jul-2016].

[32] H. Li, D. Yu, and J. E. Braun, "A Review of Virtual Sensing Technology and Application in Building Systems," HVAC\&R Res., vol. 9669, pp. 37-41, 2011.

[33] H. Tan and L. Dexter, "Improving the accuracy of sensors in building automation systems," in Proceedings of the 16th IFAC World Congress, 2005.

[34] P. Fritzson and V. Engelson, "Modelica-A unified object-oriented language for system modeling and simulation," ECOOP'98-Object-Oriented Program., vol. 1445, pp. 6790, 1998. 


\title{
A Computational Toolchain for the Automatic Generation of Multiple Reduced-Order Models from CFD Simulations
}

\author{
Thibault Marzullo* \\ School of Engineering, National University of Ireland Galway, Galway, Ireland \\ Ryan Institute, Galway, Ireland \\ Research Centre for Marine and Renewable Energy, Galway, Ireland \\ E-mail: t.marzullo1@ nuigalway.ie \\ Marcus M. Keane \\ School of Engineering, National University of Ireland Galway, Galway, Ireland \\ Ryan Institute, Galway, Ireland \\ Research Centre for Marine and Renewable Energy, Galway, Ireland \\ E-mail: marcus.keane@nuigalway.ie \\ Marco Geron \\ School of Mechanical and Aerospace Engineering \\ Queen's University Belfast, Belfast, United Kingdom \\ E-mail: $\underline{\text { m.geron@qub.ac.uk }}$ \\ Rory F.D. Monaghan \\ School of Engineering, National University of Ireland Galway, Galway, Ireland \\ Ryan Institute, Galway, Ireland \\ Research Centre for Marine and Renewable Energy, Galway, Ireland \\ E-mail: rory.monaghan@ nuigalway.ie
}

\begin{abstract}
This paper describes the development of a systematic tool chain capable of automatically extracting accurate and efficient Reduced-Order Models (ROMs) from Computational Fluid Dynamics (CFD) simulations. These ROMs can then be used to support the design and operation of Near-Zero Energy Buildings (NZEB), with a higher accuracy than traditional zonal models but at a fraction of the computational cost of CFD. This study assesses the accuracy and time to solution of these ROMs when solved for appropriate Boundary Conditions (BCs), found in the built environment, in order to define the usability envelope of the automatically extracted ROMs. The parameters used in this study are inlet temperatures $(\mathrm{K})$ and mass flow rates $(\mathrm{kg} / \mathrm{s})$. Results demonstrate that the absolute error can be maintained at under $0.5 \mathrm{~K}$ for changes in temperature of up to $\pm 15 \mathrm{~K}$, and under $0.25 \mathrm{~K}$ for changes in mass flow rates of up to $\pm 45 \%$ of the original value. The results show that this method has the potential for applications in the built environment where the ROM accuracy and low computational cost can bridge a gap between low order RC models and high order CFD, further improving the energy efficiency in smart buildings.
\end{abstract}

\section{Keywords}

CFD; ROM; buildings; zonal model 


$\begin{array}{ll}\text { Abbreviations } & \\ \text { BC } & \begin{array}{l}\text { Boundary Condition } \\ \text { Building Energy Management System } \\ \text { BEMS }\end{array} \\ \text { Computational Fluid Dynamics } \\ \text { CFD-ROM } & \text { ROMutational Fluid Dynamics - Reduced Order Model } \\ \text { MultiCFD } & \text { ROM extracted and solved for the same BCs } \\ \text { MultiROM } & \text { Near Zero Energy Buildings } \\ \text { NZEB } & \text { Reynolds Average Navier-Stokes } \\ \text { RANS } & \text { Re-Normalisation Group } \\ \text { RNG } & \text { Reduced Order Model } \\ \text { ROM } & \text { Weighted Mean Absolute Error (in K) } \\ \text { WMAE } & \end{array}$

\section{Introduction}

In the recent and ever growing global motivation for the development of the sustainable production and usage of energy, buildings are being adapted with varying degrees of "smartness". Construction materials, urban planning, architecture and systems management are being carefully optimized, as designers develop or retrofit an increasing number of buildings to render them Near Zero Energy Buildings (NZEB) in accordance with the EU Energy Performance Building Directive 2010/31/EU. With the advent of modern computing it is common to simulate parts or the entirety of a building in order to make informed design choices. In addition, smart buildings can benefit from the information gathered and processed by Building Energy Management Systems (BEMS) during their operational phase.

These systems rely not only on the accuracy of the data gathered through sensors, but also on the accuracy of computer models needed to predict a response to a certain change in energy inputs. Ideally, these models should be extremely accurate. In reality, the computational requirements of such models can become so important as to render them completely impractical. Models are therefore simplified and guided by required accuracy of the results in the intended target application domain.

\subsection{Models used in building energy simulations}

When rapid solutions are needed, domains are usually simplified as nodal models. Such models assume that entire portions of a building can be approximated by a single uniform space, or a node. This allows designers to evaluate energy consumption by running a large number of simulations, which is the case when yearly consumption estimates are needed or when the building stock of entire districts for load forecasting [1] or demand side management [2], but also towns [3] must be simulated. A review from Allegrini et al. (2015) [4] focuses on district level modelling. Nodal models can be expanded to become multi-nodal models, which allow estimation of energy exchanges within a building and provide a better representation of energy consumptions. These models are often based on electrical circuit analogy such as presented in [5] and [6] and are used for example for estimating energy consumption [7] or thermal comfort [8] in buildings.

For a more accurate description of thermal exchanges within a room or a building, zonal models are used. They subdivide a zone such as a room into several subzones and can be used to simulate effects such as thermal stratification, air plumes above convectors or air jets at HVAC inlets [9]. This type of approach is also useful when studying user thermal comfort, air mixing and indoor air quality, all of which can vary greatly within a single room. Megri et al. [9] published a review on zonal models and their applications. Zonal models usually rely on 
user expertise for the definition of each subzone. The number of sub-zones, their location in the domain and the properties of each are defined manually by the modeller, making it a timeconsuming and error-prone process.

\subsection{CFD applications in the built environment}

For studying flow patterns more closely, designers have access to Computational Fluid Dynamics (CFD) modelling technologies. The CFD modelling technique subdivides a numerical domain into many smaller finite volumes, usually hundreds of thousands to millions of computational cells. By computing partial differential Navier-Stokes, mass and energy balance equations between each cell and over the entire numerical domain, CFD simulations can provide an accurate description of flow magnitude and direction, thermal exchanges, distributions of temperature, pressure, density, and other properties.

The main drawbacks of CFD are high computational cost and the extensive user expertise needed to accurately model the boundary conditions, which have an important impact on the final results.

CFD simulations are used to assess indoor air quality and pollutant dispersion [10], thermal comfort [11], and are extensively used in studies relating to naturally ventilated buildings such as in [12]. Etheridge (2015) presents CFD as a suitable method in a review on natural ventilation [13]. CFD is also often used when simulating urban environments, in which researchers studied the effects of urban heat islands [14], wind profiles in streets [15] and around buildings [16]. Like for indoor environments, CFD is used for studies on outdoor pollutant dispersion [17]. The impact of wind canyons and densely built environments on city breathability has been simulated with CFD in [18], and likewise the impact of vegetation as seen in [19].

\subsection{CFD model order reduction}

In an effort to leverage CFD's accuracy at a fraction of the computational cost, researchers have developed techniques aimed at simplifying or extracting reduced order models (ROMs) from CFD simulations. The literature presents methods such as the Pressure Implicit with Splitting of Operator (PISO) method [20] which is derived from the Semi-Implicit Method for Pressure-Linked Equations (SIMPLE) algorithm [21] and have been developed for noniterative computation of unsteady flows and later extended to steady-state, but it has important computational costs. This can be mitigated by using semi-Lagrangian PISO [22] which has a lower computational cost than PISO. Proper Orthonormal Decomposition (POD) [23] and balanced POD [24], are used to reduce a model's number of degrees of freedom when information on the flow pattern must be captured. Fast Fluid Dynamics (FFD) [25] is derived from projection methods [26] and allows real-time solution of Navier-Stokes equations and is typically applied to wind load calculations.

Generally, the development of these models is heavily dependent on the modeller's level of expertise. Each reduced order model is developed or requires adaptation to fit a specific domain problem, and therefore requires the input of an expert. It would be beneficial to have access to a systematic automated approach to facilitate model order reduction. This study proposes a method to leverage the results from an existing CFD simulation to automatically generate rapid and accurate zonal models without additional user expertise. These zonal 
models can then be used to simulate conditions for which no CFD simulation is available while retaining a high level of accuracy within a proposed domain.

\section{Methodology}

The proposed method for ROM generation automatically extracts a multi zonal model from a CFD simulation, which can then be solved for boundary condition parameters different from the original CFD. The main advantages of this method are the level of automation, which allows generation of ROMs with minimal user input and expertise; the level of fidelity compared to CFD, which enables the ROM to retain most of the CFD simulation's accuracy; and finally the computational cost, which allows the generation of ROMs in under 60 seconds and their solution in under 0.95 seconds.

The CFD-ROM method consists in 6 main steps as shown in Figure 1: (1) the results of a CFD simulation are imported, (2) CFD computational cells are clustered together to create zones, which are uniform volumes of air, (3) interactions between zones and between zones and domain boundaries are processed, (4) a ROM is generated and (5) solved, and finally (6) the solved ROM is remapped back to the CFD domain.

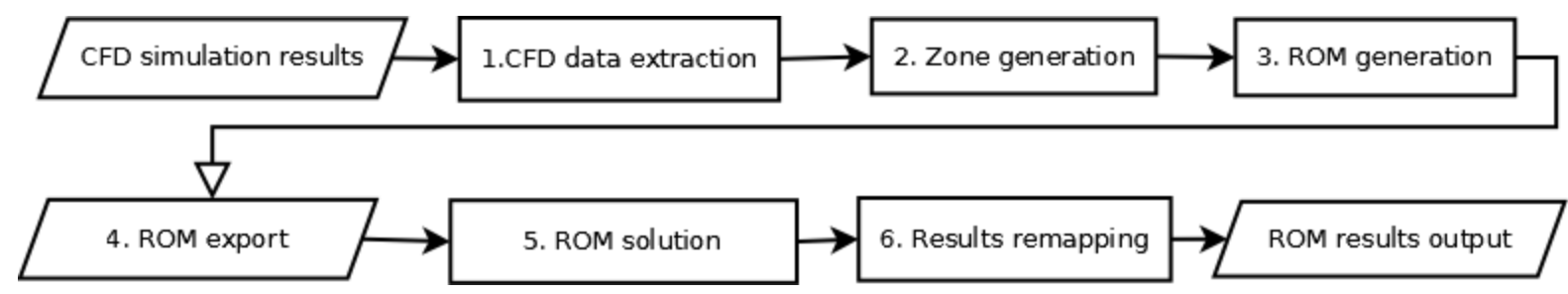

Figure 1: CFD-ROM method flowchart outlining the main steps of the method.

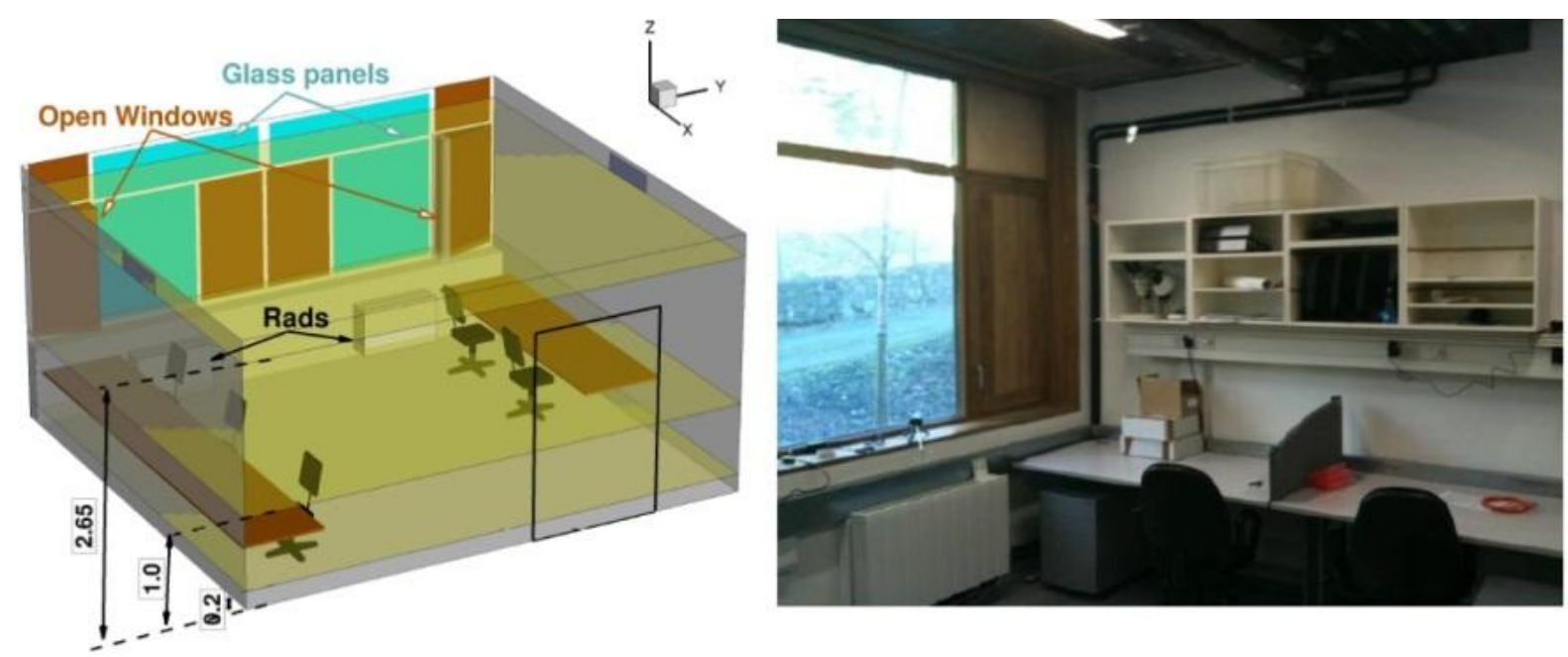

Figure 2: Numerical and physical domain of the ERI building office modelled in CFD

This section presents the methods used in the development of the algorithms in Python [27] for extraction and solution of the ROMs. Firstly, it presents the CFD simulations on which the ROMs have been tested and assessed, then the principles of zone generation, ROM generation and solution are explained. 


\subsection{CFD Simulations and Validation}

The data used in this comparative study are taken from the previously-validated CFD model of a north-facing office in the Environmental Research Institute (ERI) building at University College Cork (UCC), shown in Figure 2 [28]. The office measures $5.2 \mathrm{~m}$ (length) by $5.6 \mathrm{~m}$ (width) by 2.9 (height). Its furniture includes five desks and chairs and shelf units. Two fan convectors heat the office and two automated windows are present. No other sources of heating, such as computers or people, are present. Steady state CFD models were developed using the Phoenics modelling software [29], which uses an immersed body technique. Therefore, a Cartesian structured grid was defined with 1,572,165 cells (115x147x93). Turbulence was modelled using the Reynolds Average Navier-Stokes (RANS) approach coupled with the Re-Normalisation Group (RNG) $k-\varepsilon$ turbulence model. Air was modelled as an incompressible ideal gas. The ceiling, floor, east and west walls were assumed to have a constant temperature. All other objects are considered adiabatic. All CFD simulations used have been validated with experimental data and previously published [28].

The CFD domain energy sources are listed in Table 1. In the case used for this study, the windows and door are closed and the two convectors are in an on state. The domain includes two air vents located on the east and west walls close to the ceiling. The two convectors are located on the north wall, close to the windows.

Table 1: CFD simulation base boundary conditions

\begin{tabular}{|c|c|c|c|}
\hline Boundary & Comment & Type & Base value \\
\hline \multicolumn{4}{|c|}{ Convectors } \\
\hline East convector & & Air inlet & $\begin{array}{l}\mathrm{T}_{\text {Econvector }}=45^{\circ} \mathrm{C} \\
\dot{\mathrm{m}}_{\text {Econvector }}=0.048 \mathrm{~kg} \cdot \mathrm{s}^{-1}\end{array}$ \\
\hline West convector & & Air inlet & $\begin{array}{l}\mathrm{T}_{\mathrm{Wconvector}}=45^{\circ} \mathrm{C} \\
\dot{\mathrm{m}}_{\mathrm{Wconvector}}=0.048 \mathrm{~kg} \cdot \mathrm{s}^{-1}\end{array}$ \\
\hline \multicolumn{4}{|c|}{ Walls } \\
\hline Ceiling & & Constant temperature & $\mathrm{T}_{\text {ceiling }}=23.2^{\circ} \mathrm{C}$ \\
\hline Floor & & Constant temperature & $\mathrm{T}_{\text {floor }}=18^{\circ} \mathrm{C}$ \\
\hline East wall & & Constant temperature & $\mathrm{T}_{\text {Ewall }}=20^{\circ} \mathrm{C}$ \\
\hline West wall & & Constant temperature & $\mathrm{T}_{\mathrm{Wwall}}=20^{\circ} \mathrm{C}$ \\
\hline \multicolumn{4}{|c|}{ Windows } \\
\hline East window & Closed & Air inlet & $\begin{array}{l}\mathrm{T}_{\text {Ewindow }}=9.35{ }^{\circ} \mathrm{C} \\
\dot{\mathrm{m}}_{\text {Ewindow }}=0 \mathrm{~kg} \cdot \mathrm{s}^{-1}\end{array}$ \\
\hline West window & Closed & Air inlet & $\begin{array}{l}\mathrm{T}_{\mathrm{W}_{\text {window }}}=8.3^{\circ} \mathrm{C} \\
\dot{\mathrm{m}}_{\mathrm{W} \text { window }}=0 \mathrm{~kg} \cdot \mathrm{s}^{-1}\end{array}$ \\
\hline \multicolumn{4}{|c|}{ Other openings } \\
\hline East vent & & Opening & $\begin{array}{l}\mathrm{T}_{\text {Event }}=20.2^{\circ} \mathrm{C} \\
\mathrm{P}_{\text {Event }}=1.013 \times 10^{5} \mathrm{~Pa}\end{array}$ \\
\hline West vent & & Opening & $\begin{array}{l}\mathrm{T}_{\text {Wvent }}=20.7^{\circ} \mathrm{C} \\
\mathrm{P}_{\text {Wvent }}=1.013 \times 10^{5} \mathrm{~Pa}\end{array}$ \\
\hline Door & Closed & & $\dot{\mathrm{m}}_{\text {door }}=0 \mathrm{~kg} \cdot \mathrm{s}^{-1}$ \\
\hline
\end{tabular}

\subsection{Zone Generation}

As stated previously, ROMs are created by clustering computational cells of the CFD domain, together depending on their position and their zone criterion. Zone criteria include any 
variable for which clustering is demanded, including for example temperature, density and air velocity. The method currently uses one criterion at a time, and the ROMs presented in this study have been generated with cell temperature as the zone criterion.

Firstly, zone-types are defined. A zone-type is a group of cells associated with a particular zone criterion over a specific interval, for example, temperatures. Such intervals are defined as follows: first the mean value of the temperature is processed over the entire CFD domain. Two zone-types are then defined: a zone-type containing all the cells in which temperature is higher than the mean value, and another containing all the cells in which temperature is lower or equal to the mean value. Subsequently the zone-types are iteratively subdivided into smaller zone-types, according to the mean value of temperature within each zone-type.

As a result, $2^{n}$ zone-types are defined, with $n$ the number of times this process is repeated. The user has control over the number of zone-types as this affects the discretization process. More zone-types allow a higher fidelity to the original CFD, but higher computational costs incur as discussed in the Results section.

Once zone-types have been defined for the ROM, the algorithm starts assigning cells to zones as shown in Figure 3. A zone is a cluster of computational cells which (1) are adjacent and (2) belong to the same zone-type. The algorithm starts by creating an empty zone and populates it with the first computational cell it finds.

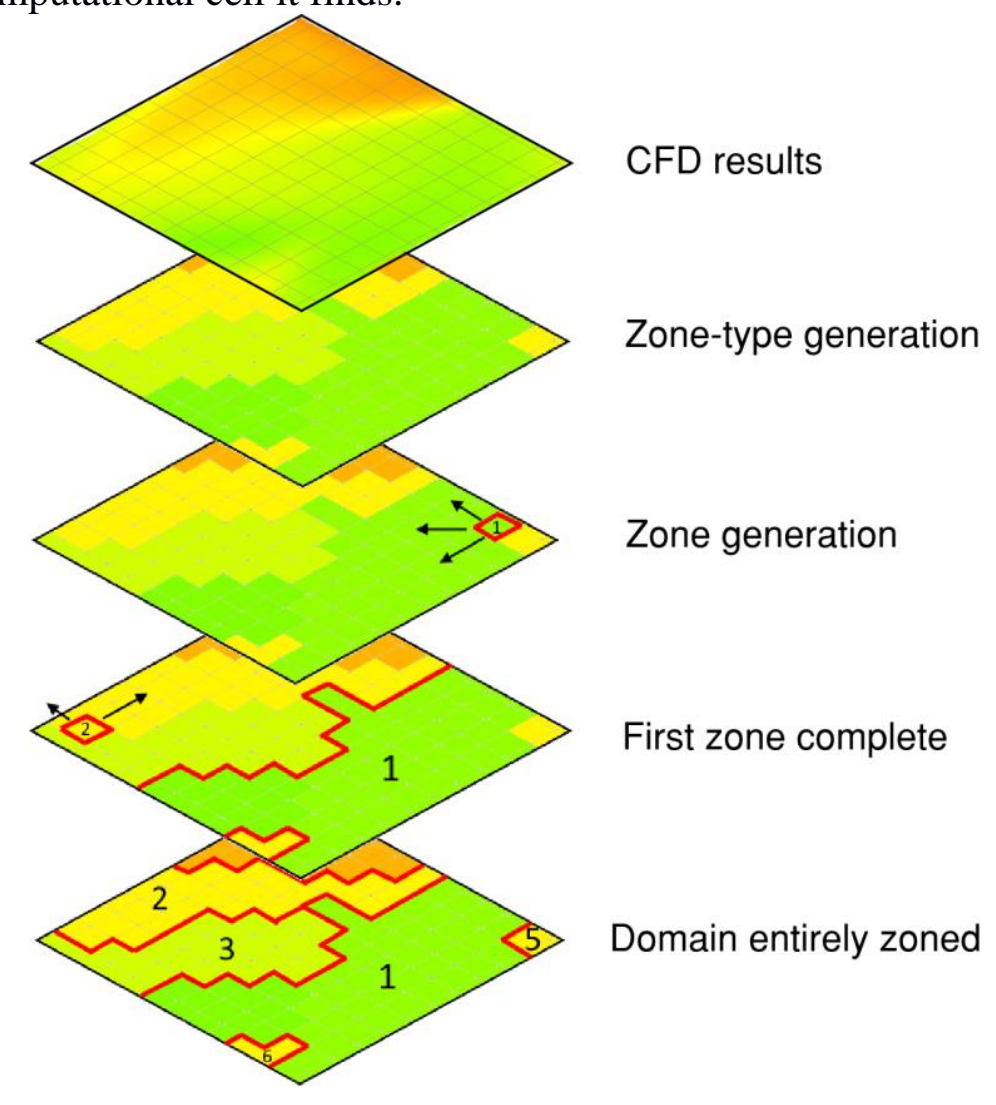

Figure 3: Representation of the zone generation algorithm in 2 dimensions. The algorithm first defines zone-types and then assigns all adjacent cells of the same zone-type to a new zone.

The cells adjacent to this initial cell are scanned, and if they belong to the same zone-type they are added to the zone. The same process is repeated for all the cells in the same zone, until no more suitable cells are found. At that point the algorithm creates a new zone and 
repeats the process until all the cells of the domain are assigned to a zone. A previous study [30] by the authors assessed the accuracy of various zone generation algorithms.

Computationally, at this point the original CFD domain has been discretized from the original large number of cells to the final reduced number of zones. Each zone is lumped into a node of the fluid network representing the domain. In order to generate a ROM, it is then necessary to process interactions between fluid nodes, and between fluid nodes and boundary nodes.

\subsection{ROM Generation}

The first step in the ROM generation is to consider zones as uniform volumes in the CFD domain. The average values of temperature, density, and pressure are computed over the cells belonging to each zone in order to obtain the uniform zone properties.

Next, the zone-zone interactions must be computed. The algorithm calculates the mass flow rates at the zone-zone interfaces by selecting all cells that have a neighbour assigned to a different zone and computing the unitary mass flow rate at the interface between these two neighbouring cells. The total mass flow rate between zones is calculated as the sum of all the unitary mass flow rates at the zone-zone interface.

After computing the zone-zone interactions, the algorithm detects the sources of energy such as air inlets and non-adiabatic walls. In a similar fashion to zone-zone interactions, the mass flow rates of inlets/outlets into/from each zone are computed at their interface and the total mass flow rate between an inlet/outlet and a zone is the sum of all unitary mass flow rates. Finally, the thermal boundaries such as non-adiabatic walls are assumed uniform, they are assigned an average temperature and a constant UA depending on their contact area with each zone.

\subsection{ROM Solution}

The ROMs are solved with Sinda/FLUINT [31], a commercial software for finite-difference lumped parameter fluid flow analysis of complex systems. The data generated from zone properties and interactions with the domain are compiled to respect Sinda/FLUINT's input format: (1) zones are translated into "tanks", which are lumps of constant volume and uniform properties (temperature, density, pressure); (2) inlets and outlets are translated into "plena", which are similar lumps but with infinite volume; and (3) walls and other purely thermal sources are each translated to a thermal node, with uniform temperature. A thermal and fluid network is then created, linking these elements through corresponding interactions: mass exchange between fluid lumps, and heat exchange between fluid lumps and thermal nodes. Mass exchanges are computed directly from the mass flow rates at zone-zone interfaces found previously, and heat exchanges are computed from a constant UA defined between each zone and thermal boundary. Once the model is solved, Sinda/FLUINT returns the steady-state solution with properties for each lump which can then be mapped back to the original CFD domain for comparison.

\subsection{Error measurement}

The present study uses the weighted mean absolute error (WMAE) in units of Kelvin, shown in Equation 1. The weighting corresponds to the volume of each cell relative to the total volume of the domain, in order to account for non-uniform cell volumes, especially close to the boundaries where the CFD mesh is finer. 
$W M A E=\sum_{i=0}^{n} \frac{V_{i} \times\left|T_{C F D i}-T_{i}\right|}{V_{\text {domain }}}$

Where $\mathrm{n}$ is the number of cells in the domain, $\mathrm{V}_{\mathrm{i}}$ is the volume of cell $\mathrm{i}, \mathrm{V}_{\text {domain }}$ is the total volume of the domain, $T_{\text {CFDi }}$ is the original $C F D$ temperature of cell $i$, and $T_{i}$ is the temperature assigned to the cell after solving the ROM.

\section{Results}

This study presents the results obtained when modifying the parameters of a ROM to predict temperature distributions for BCs that differ from the ones of the original CFD simulations.

In order to achieve this, a set of CFD simulations was generated. For the same computational domain, simulations were solved featuring different inlet temperatures and mass flow rates. Table 2 presents the sets of parameters for boundary conditions used in this study. The CFD simulations, CFD-ROM program and ROM solver have been run on the same desktop computer (Intel Core i7-4790, 8GB RAM). The cases range from $\mathrm{T}-10$ to $\mathrm{T}+15$ for temperature, including $\mathrm{T}+5 \mathrm{~b}$ where only the temperature of the west convector is modified leaving the east one to $45^{\circ} \mathrm{C}$ (the base temperature); and from $\mathrm{M}-45 \%$ to $\mathrm{M}+100 \%$ for mass flow rates at the convectors.

Table 2: list of boundary conditions parameters used in MultiROM and MultiCFD

\begin{tabular}{ccc}
\hline Variable & Cases & Values \\
\hline Temperature $\left(\mathrm{T}_{\text {convector }}\right)$ & $\mathrm{T}-10$ & $35^{\circ} \mathrm{C}$ \\
& $\mathrm{T}-5$ & $40^{\circ} \mathrm{C}$ \\
& Base & $45^{\circ} \mathrm{C}$ \\
& $\mathrm{T}+5 \mathrm{~b}$ & $50^{\circ} \mathrm{C}(\mathrm{West}) \& 45^{\circ} \mathrm{C}$ (East) \\
& $\mathrm{T}+5$ & $50^{\circ} \mathrm{C}$ \\
& $\mathrm{T}+10$ & $55^{\circ} \mathrm{C}$ \\
Mass flow rates $\left(\dot{\mathrm{m}}_{\text {convectors }}\right)$ & $\mathrm{T}+15$ & $60^{\circ} \mathrm{C}$ \\
\hline & $\mathrm{M}-45 \%$ & $0.0528 \mathrm{~kg} . \mathrm{s}^{-1}$ \\
& $\mathrm{M}-30 \%$ & $0.0672 \mathrm{~kg} . \mathrm{s}^{-1}$ \\
& $\mathrm{Base}$ & $0.096 \mathrm{~kg} . \mathrm{s}^{-1}$ \\
& $\mathrm{M}+30 \%$ & $0.1248 \mathrm{~kg} . \mathrm{s}^{-1}$ \\
& $\mathrm{M}+45 \%$ & $0.1392 \mathrm{~kg} . \mathrm{s}^{-1}$ \\
\hline $\mathrm{M}+60 \%$ & $0.1536 \mathrm{~kg} . \mathrm{s}^{-1}$ \\
\hline
\end{tabular}

ROMs have been generated for zone numbers ranging from 2 to 51 in order to define at which point the error converges. The error quickly decreases for 2-11 zones then stabilizes around 22 zones and is nearly constant thereafter, as shown in Figure 4, while the corresponding solution times vary from $0.9 \mathrm{~s}$ for 2 zones to $1.1 \mathrm{~s}$ for 51 zones, against 6 to 7 hours for the CFD simulation. Therefore, the ROMs presented in this study are in the 20-25 zones range, since while the user can demand a certain number of zones, there are occasionally a limited number of odd zones created to accommodate large temperature gradients in the domain. The error in this case is particularly low because the extracted ROM is solved for the same BCs as the original CFD simulation, and as such it does not represent the intended use for the CFDROM method. The following section presents the results in the case of ROMs being solved for a different set of BCs and for which CFD results are not available, as would ideally be the case for the application of the CFD-ROM method. 


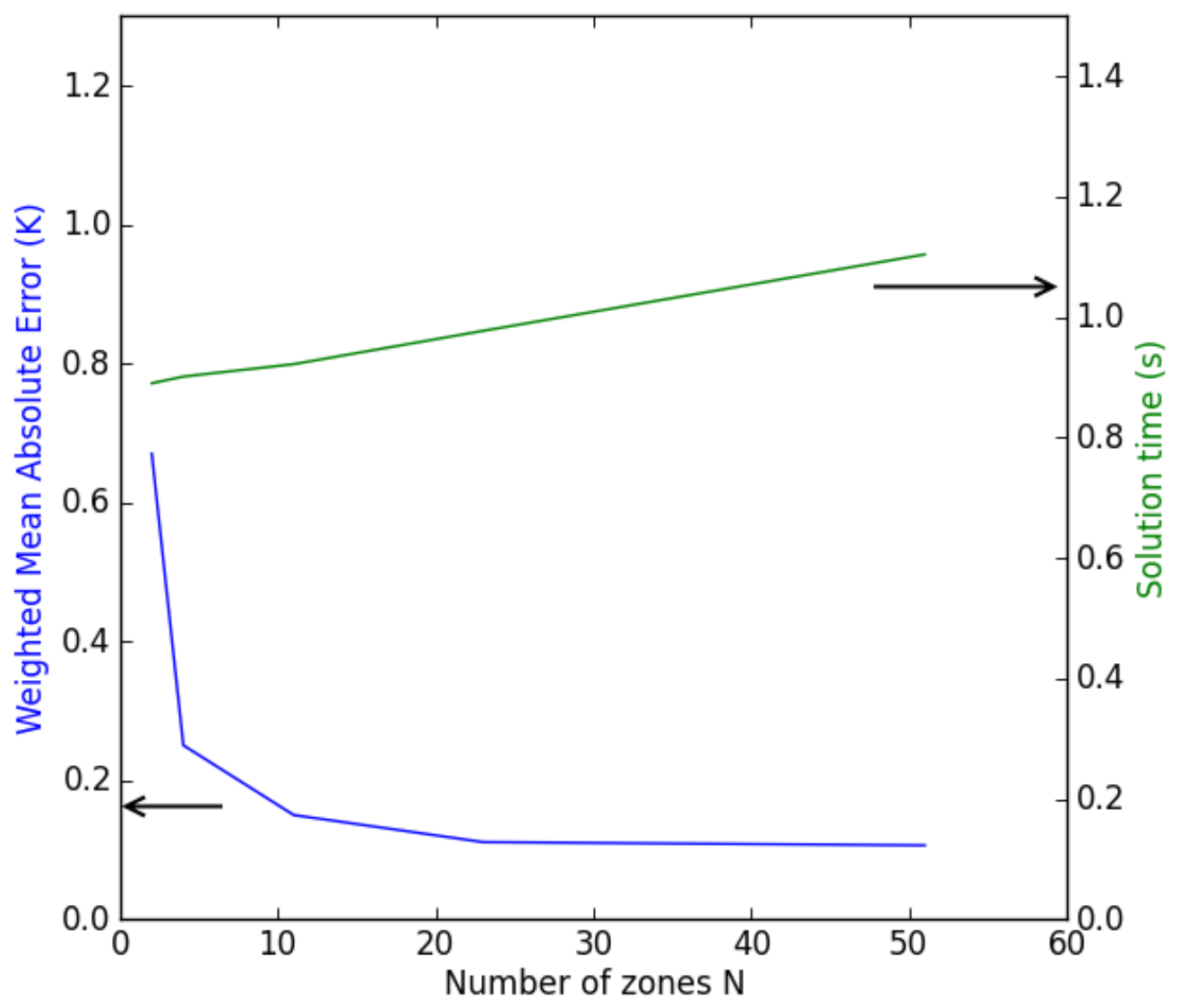

Figure 4: ROM size independence study.

\subsection{ROM accuracy when varying boundary condition parameters}

Two ROM case studies were generated to (i) measure the impact that changing the ROM parameters has on ROM accuracy, and (ii) assess the usability envelope of ROMs. The first, called "MultiCFD", uses a ROM generated directly from the corresponding CFD case. It serves as a basis for estimating the relative accuracy of the second case study, called "MultiROM", in which a ROM is generated from the base CFD case and subsequently solved with the new BC parameters. Developing a method for generating flexible and accurate MultiROMs is the main objective of this research. The aim is to provide designers and operators with a tool that would allow them to simulate the built environment when multiple CFD simulations are either unavailable or impractical.

The modelled office and its corresponding CFD simulation feature two convectors for which a temperature and air velocity are defined. This study assesses the accuracy of ROMs when (1) the convectors temperature $\mathrm{T}_{\text {convector, }}$, and (2) their mass flow rate $\dot{\mathrm{m}}_{\text {convector }}$ are changed. The ROMs are extracted from the "base" CFD case, then their parameters are changed to match the other CFD cases, the ROMs are solved and finally their outputs are compared to the corresponding CFD case results.

The first test was to replicate previous results by the authors obtained when varying only temperatures by $\pm 5 \mathrm{~K}$ around the base temperature, then to reach $+15 \mathrm{~K}$ of variation around the base temperature. Figure 5 shows the absolute error for each case, in both MultiCFD and MultiROM scenarios. The ROMs show a good level of accuracy when solved for this range of parameters, considering the $\pm 0.6 \mathrm{~K}$ uncertainty range of temperature sensors commonly met 
in the built environment [32]. When the temperature is increased above the base temperature, the error is generally higher than ROMs solved for a temperature below the base temperature. This is a result of the immutability of the ROM's zones once they have been generated for the base case. The algorithm generates a fixed number of zones that cannot be changed after generation. In order to capture certain features, such as large temperature gradients, the algorithm will generate more zones around each feature. In the case of large temperature gradients, the number of zones depends on the amplitude of the gradient: the greater the gradient, the more zones are created. After generation of a ROM from the base case, when it is solved for lower temperatures the gradient is lower and the ROM therefore contains an excess of zones (from the base case) to characterize the smaller gradient, resulting in a smaller error. Conversely, when the ROM is solved for higher temperatures the pre-existing number of zones is not sufficient to capture the larger temperature gradient, resulting in a larger error. The second, and novel, set of results was generated by varying the convectors mass flow rates. In order to achieve this, an additional function was added to the code to ensure that the ROM mass flow rates were all balanced, as changing the inlets mass flow rates would alter the balance. This step is done in a purely mathematical manner, where zone by zone the inflows and outflows are iteratively balanced to match the new BCs. A connectivity table is generated by comparing the proportion of inflows and outflows from and to each zone and assigning weights to each, so that the general trend of mass exchange in the domain is respected in the modified ROM. The results are presented in Figure 6 and show that up to $\pm 45 \%$ of change in mass flow rates at the convectors, the ROM still has an absolute error under $0.5 \mathrm{~K}$ versus $0.11 \mathrm{~K}$ of error for the base, unmodified case - with the exception of the $+45 \%$ case with $0.84 \mathrm{~K}$ of absolute error. This again falls into the uncertainty range of common temperature sensors.

A similar trend exists of higher error for an increase in mass flow rates compared to a lower error for decreased mass flow rates when solving the ROM. This again is due to the immutability of zones once they have been generated, which cannot accommodate a change in flow shape.

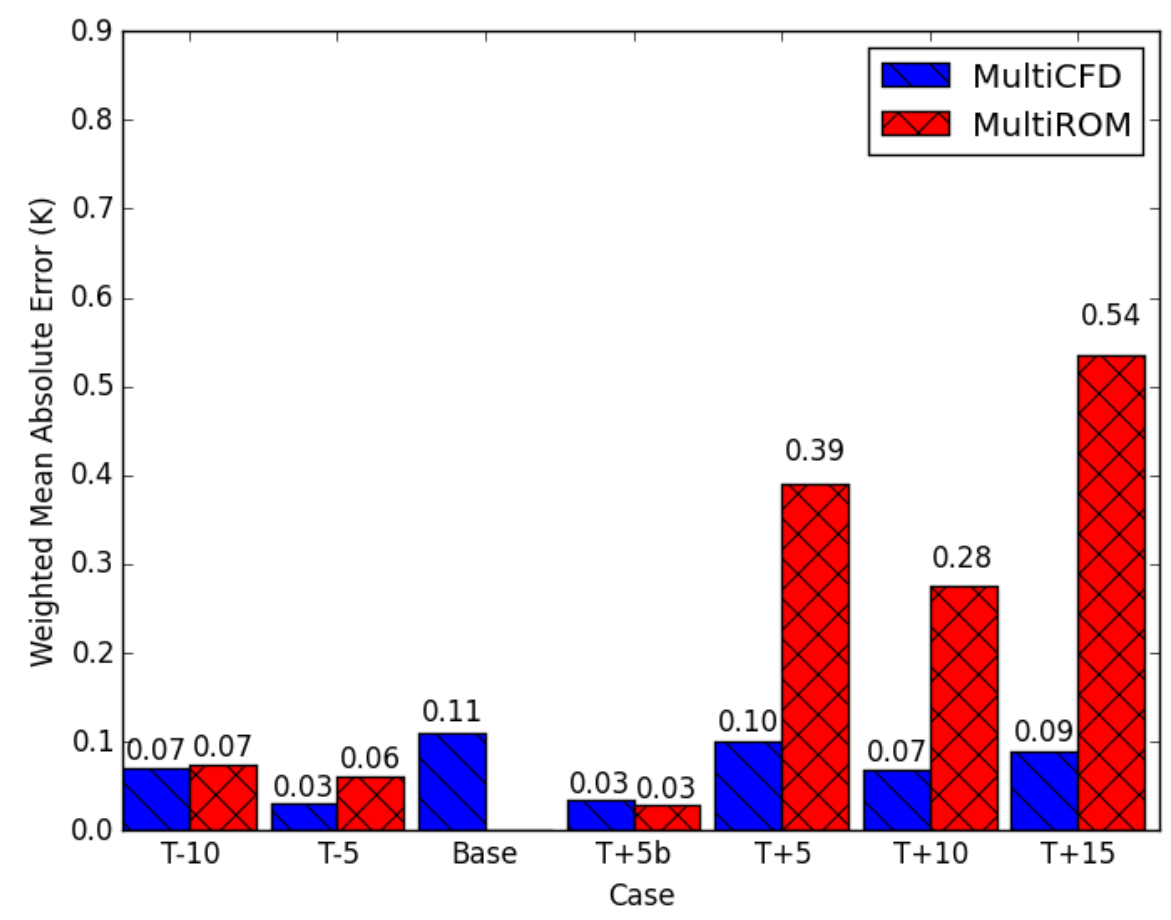

Figure 5: MultiCFD and MultiROM error when changing BC temperatures. 


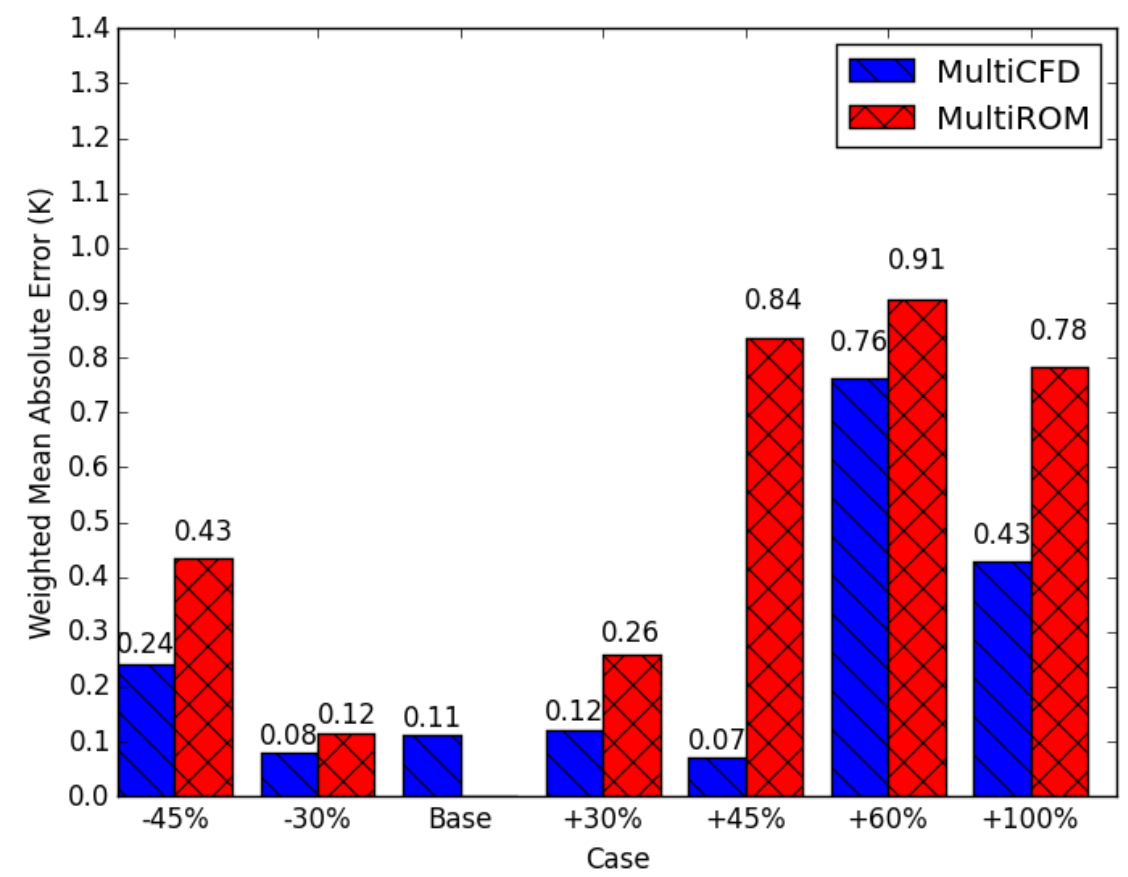

Figure 6: MultiCFD and MultiROM error when changing BC mass flow rates

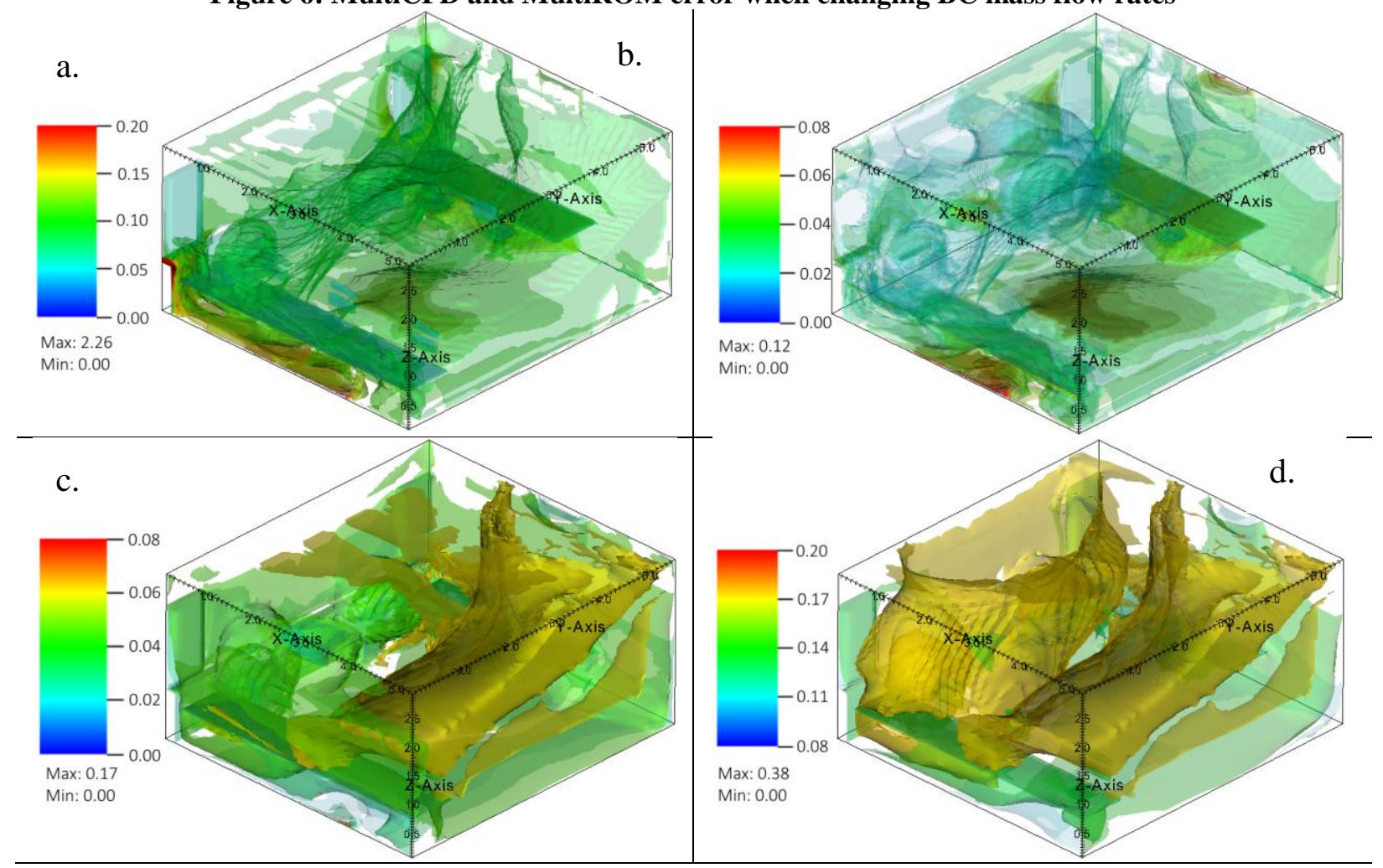

Figure 7: Iso-surface WMAE (in K) plots of cases (a) $\dot{\mathrm{m}}-\mathbf{4 5} \%$, (b) $\dot{\mathrm{m}}-\mathbf{3 0} \%$, (c) $\dot{\mathrm{m}}+\mathbf{3 0} \%$ and (d) $\dot{\mathrm{m}}+\mathbf{4 5 \%}$.

\subsection{Error plots}

A study of the local error was done in order to assess more finely the fidelity of the ROMs against the original CFD simulations. Figure 7 shows semi-opaque iso-surface plots of the m$45 \%$ to $\dot{\mathrm{m}}+45 \%$ cases. No peaks in local error stand out, except for a very limited number of odd cells due to minor computational errors. Such errors are due to a mechanism that prevents the algorithm from generating very small zones, which is necessary to avoid assigning too 
many zones to areas with large temperature gradients. These small zones would not be representative of the flow pattern, but their presence lowers the overall accuracy of the ROM as less zones are available for zoning the remainder of the domain. Without this mechanism, the ROMs would be able to capture large temperature gradients very finely but would be unable to capture stratification.

Results are identical for the $\mathrm{T}-10$ to $\mathrm{T}+15$ cases, suggesting that the algorithm is able to accurately capture the domain's thermal distribution, including the volumes with high temperature gradients such as above and around the convectors. Figure 8 shows a X-Z slice of the domain at the centre of the west convector and shows how the CFD-ROM method captures both the heat plume above the convector and also temperature stratification in the room. The limited error visible around the heat plume shows that setting a lower limit to the size of zones does not adversely affect to a great extent the algorithm's ability to capture high temperature gradients, while allowing it to also capture smaller variations in temperature.
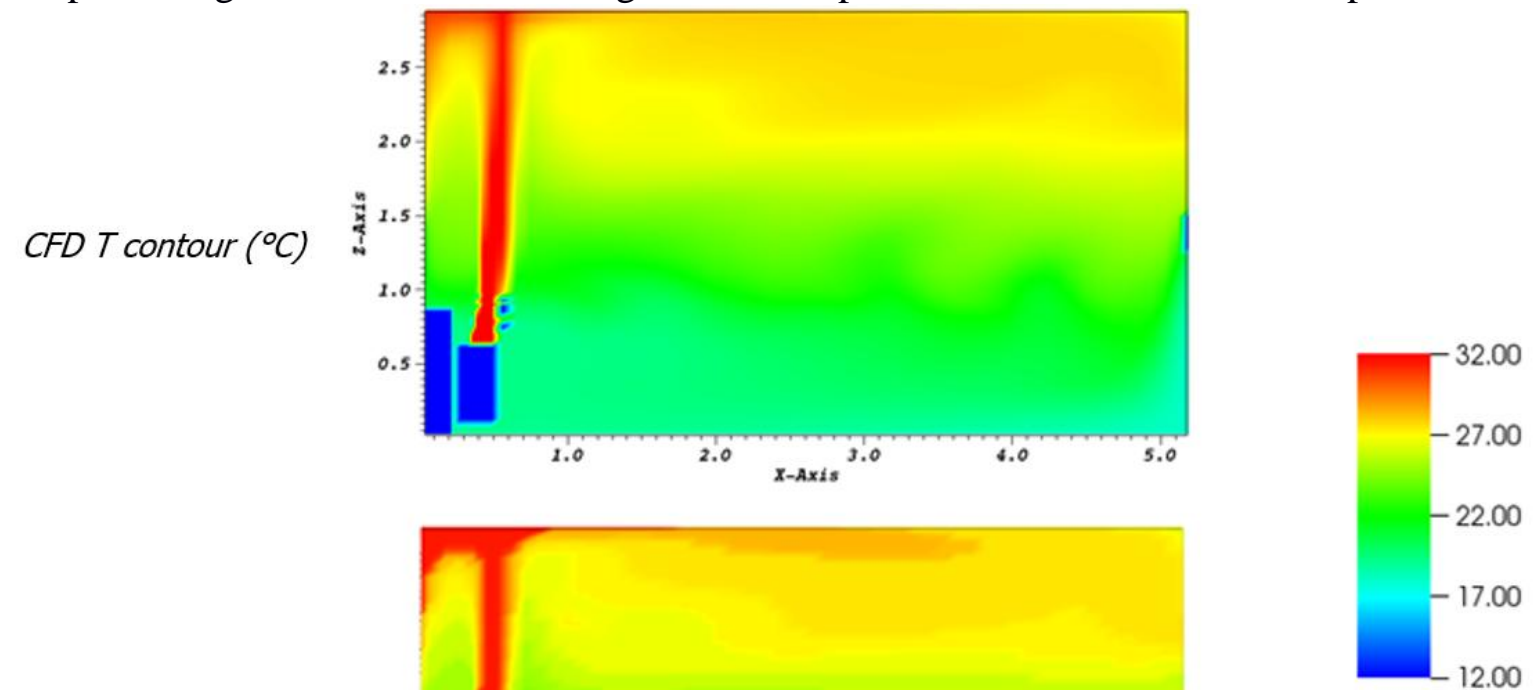

ROM T contour $\left({ }^{\circ} \mathrm{C}\right)$

Error (\%)
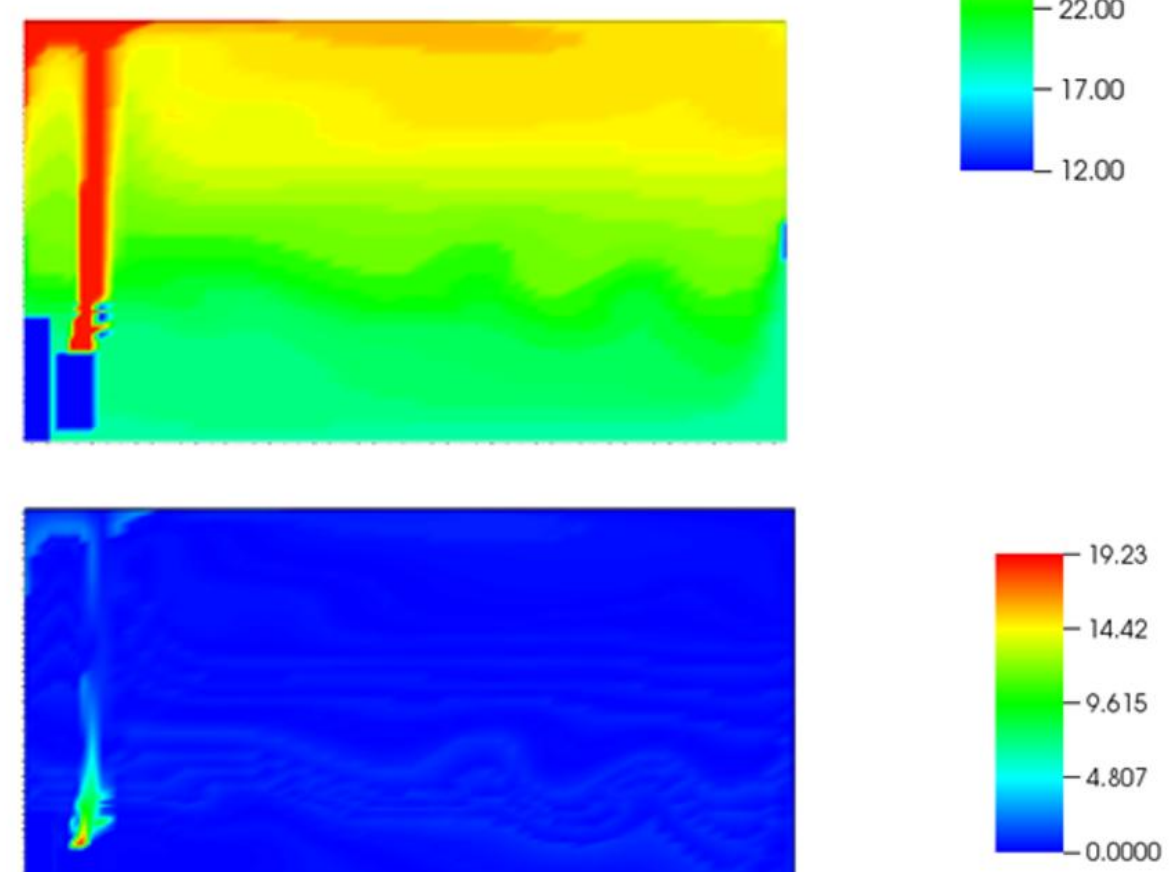

Figure 8: CFD temperature contour, ROM solution, and error plot of a X-Y slice at the centre of the west convector

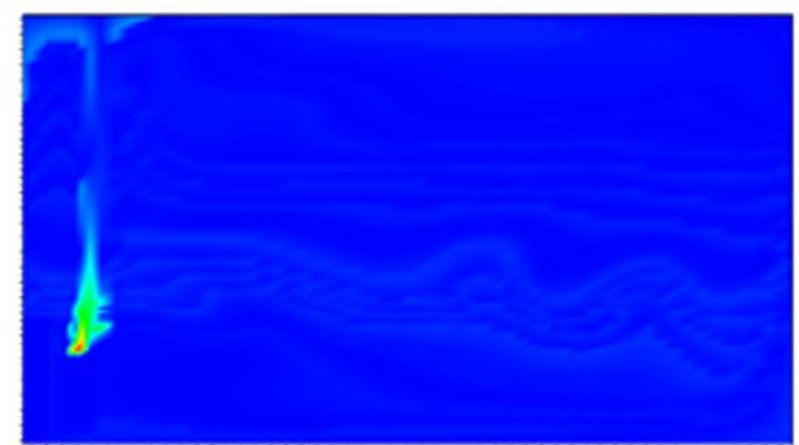




\section{Discussion}

This study showed that it is possible to extract multi-zonal ROMs from CFD simulations with high fidelity and in real time for application domains in the built environment. These findings can be mitigated by the relative simplicity of the case study utilised in this research, where only two convectors and two vents are present in the domain. Further research must be done on other indoor environments, such as open-space offices, theatre rooms or sports complexes in order to assess the usability of the method in more complex environments featuring larger spaces and openings, air vents, HVAC outlets, which could affect the accuracy of the ROMs.

Furthermore, it is currently up to the end user to select an appropriate number of zones for the ROM. An extreme example would be the selection of a 20-zone ROM in a domain with 19 air inlets: the algorithm would use 19 of the available zones to capture the air inlets, and only one to capture the rest of the domain. In order to generate a more appropriate number of zones it might be beneficial to set an upper limit to the size of each zone, so that the algorithm could if needed increase the number of zones without user input. There is a certain room for expansion in the number of zones, as this study has shown that the difference in time to solution between 3 and 50 zones is not significant and 20-25 zones are enough to model the presented case, yet further research must be done on complex scenarios to certify the usability of this method for larger numbers of zones.

In both studies, when varying temperature and mass flow rates the ROMs are generally more accurate when lowering the parameters values than they are when the values are increased. When solving for different BCs, the parameters computed on the base case are not valid anymore and lead to increasing error as the new ROM differs more and more from the base case. This is likely caused by the immutability of zones after they have been generated from the base case and the assumptions made when compiling the model for Sinda/FLUINT, namely the constant values assigned to zone-zone mass flow rates and wall heat transfers. An improvement upon the current iteration of the method will be the implementation of variable mass flow rates and heat transfers. The asymmetrical change in error, lower when temperatures are colder and mass flow rates weaker, is due to the fact that the domain becomes more and more uniform as the energy flow in the domain is lower, in which case the ROM has more zones than necessary to compute the new temperature distributions. Increasing the number of zones globally lowers the error but the asymmetry is still present to some extent.

Nevertheless, the results are encouraging when considering the usual $\pm 0.6 \mathrm{~K}$ uncertainty of temperature sensing techniques in the built environment [32]. The possibility to change boundary temperatures by $\pm 15 \mathrm{~K}$ and mass flow rates by $\pm 45 \%$ while maintaining an acceptable level of accuracy allows the consideration of, for example, thermal comfort and HVAC control as potential applications for which further research must be done.

Additionally, the authors consider the inclusion of multiple-criteria zone generation, versus the current single-criterion zone generation, as an important upgrade to the algorithm which may improve its accuracy especially when mass flow rates must be changed. 


\section{Conclusion}

The accuracy of CFD is recognized to have a potentially substantial impact on building energy consumption through methods such as virtual sensing [33]. Unfortunately, the computational costs involved in solving a CFD model render it unpractical for real-time applications such as BEMS. This study proposed a method capable of extracting ROMs from CFD simulations and solving them in near real-time. First an ROM size independence study was conducted, showing that it can be achieved for 20 to 25 zones for the presented case. The accuracy of ROMs that were solved and assessed for (1) different temperature BCs and (2) different mass flow rates. It was shown that it was possible to obtain accurate results, in real time, for boundary conditions that were different from the original CFD BCs. These multizonal ROMs have an accuracy comparable to the uncertainty in sensing equipment used in the built environment, thus rendering them useful in applications such as virtual sensing. This enables the use of CFD-ROM for thermal comfort assessment, BEMS, and applications where the unavailability of real-time zonal models is detrimental.

However, it is necessary to apply this method to more complex scenarios in order to confirm its advantages in terms of rapidity and accuracy, and it is also necessary to include additional features such as multi-criteria zone generation and a radiation model. Currently the authors are studying CFD simulations of a highly glazed, naturally ventilated room to further improve the CFD-ROM method, and look forward to applying the method to larger, more complex cases.

The next steps in the development of the CFD-ROM toolchain are: (1) the generation of ROMs for different indoor environments, such as highly glazed, naturally ventilated rooms; (2) the investigation of techniques that would improve ROMs accuracy when solving for different inlet mass flow rates; (3) the inclusion of a radiation model; and (4) the development of a tailored solver in the open-source language Modelica [34].

\section{Acknowledgements}

The authors wish to acknowledge the following funding. T. Marzullo is supported by a Scholarship from the College of Engineering and Informatics at NUI Galway and by HIT2GAP (EU/H2020 Grant Agreement No.: 680708).

\section{References}

[1] W. Ma, S. Fang, G. Liu, and R. Zhou, "Modeling of district load forecasting for distributed energy system," Appl. Energy, vol. 204, pp. 181-205, Oct. 2017.

[2] H. Cai, C. Ziras, S. You, R. Li, K. Honoré, and H. W. Bindner, "Demand side management in urban district heating networks," Appl. Energy, vol. 230, pp. 506-518, Nov. 2018.

[3] P. Nageler, G. Schweiger, H. Schranzhofer, T. Mach, R. Heimrath, and C. Hochenauer, "Novel method to simulate large-scale thermal city models," Energy, vol. 157, pp. 633-646, Aug. 2018.

[4] J. Allegrini, K. Orehounig, G. Mavromatidis, F. Ruesch, V. Dorer, and R. Evins, “A review of modelling approaches and tools for the simulation of district-scale energy systems," Renew. Sustain. Energy Rev., vol. 52, pp. 1391-1404, Dec. 2015.

[5] G. Fraisse, C. Viardot, O. Lafabrie, and G. Achard, "Development of a simplified and accurate building model based on electrical analogy," Energy Build., vol. 34, no. 10, pp. 
1017-1031, 2002.

[6] J. Hillary, E. Walsh, A. Shah, R. Zhou, and P. Walsh, "Guidelines for developing efficient thermal conduction and storage models within building energy simulations," Energy, vol. 125, pp. 211-222, Apr. 2017.

[7] V. S. K. V. Harish and A. Kumar, "Reduced order modeling and parameter identification of a building energy system model through an optimization routine," Appl. Energy, vol. 162, pp. 1010-1023, 2016.

[8] P. H. Shaikh, N. B. M. Nor, P. Nallagownden, I. Elamvazuthi, and T. Ibrahim, "A review on optimized control systems for building energy and comfort management of smart sustainable buildings," Renew. Sustain. Energy Rev., vol. 34, pp. 409-429, 2014.

[9] A. C. Megri and F. Haghighat, "Zonal Modeling for Simulating Indoor Environment of Buildings: Review, Recent Developments, and Applications," HVAC\&R Res., vol. 13:6, pp. 887-905, 2007.

[10] B. Blocken, Y. Tominaga, and T. Stathopoulos, "CFD simulation of micro-scale pollutant dispersion in the built environment," Build. Environ., vol. 64, pp. 225-230, Jun. 2013.

[11] X. Zhao, W. Liu, D. Lai, and Q. Chen, "Optimal design of an indoor environment by the CFD-based adjoint method with area-constrained topology and cluster analysis," Build. Environ., vol. 138, pp. 171-180, Jun. 2018.

[12] T. van Hooff and B. Blocken, "CFD evaluation of natural ventilation of indoor environments by the concentration decay method: $\mathrm{CO} 2$ gas dispersion from a semienclosed stadium," Build. Environ., vol. 61, pp. 1-17, Mar. 2013.

[13] D. Etheridge, "A perspective on fifty years of natural ventilation research," Build. Environ., vol. 91, pp. 51-60, Sep. 2015.

[14] A. Mochida and I. Y. F. Lun, "Prediction of wind environment and thermal comfort at pedestrian level in urban area," J. Wind Eng. Ind. Aerodyn., vol. 96, no. 10-11, pp. 1498-1527, Oct. 2008.

[15] P. Moonen, V. Dorer, and J. Carmeliet, "Evaluation of the ventilation potential of courtyards and urban street canyons using RANS and LES," J. Wind Eng. Ind. Aerodyn., vol. 99, no. 4, pp. 414-423, Apr. 2011.

[16] B. Blocken and J. Persoon, "Pedestrian wind comfort around a large football stadium in an urban environment: CFD simulation, validation and application of the new Dutch wind nuisance standard," J. Wind Eng. Ind. Aerodyn., vol. 97, no. 5-6, pp. 255-270, Aug. 2009.

[17] J. Hang, Y. Li, M. Sandberg, R. Buccolieri, and S. Di Sabatino, "The influence of building height variability on pollutant dispersion and pedestrian ventilation in idealized high-rise urban areas," Build. Environ., vol. 56, pp. 346-360, Oct. 2012.

[18] R. Buccolieri, M. Sandberg, and S. Di Sabatino, "City breathability and its link to pollutant concentration distribution within urban-like geometries," Atmos. Environ., vol. 44, no. 15, pp. 1894-1903, May 2010.

[19] C. Gromke, R. Buccolieri, S. Di Sabatino, and B. Ruck, "Dispersion study in a street canyon with tree planting by means of wind tunnel and numerical investigations Evaluation of CFD data with experimental data," Atmos. Environ., vol. 42, no. 37, pp. 8640-8650, Dec. 2008.

[20] R. I. Issa, "Solution of the implicitly discretised fluid flow equations by operatorsplitting," J. Comput. Phys., vol. 62, no. 1, pp. 40-65, 1986.

[21] S. . Patankar and D. . Spalding, "A calculation procedure for heat, mass and momentum transfer in three-dimensional parabolic flows," Int. J. Heat Mass Transf., vol. 15, no. 10, pp. 1787-1806, Oct. 1972.

[22] Y. Xue, W. Liu, and Z. (John) Zhai, "New semi-Lagrangian-based PISO method for 
fast and accurate indoor environment modeling," Build. Environ., vol. 105, pp. 236244, 2016.

[23] H. P. Bakewell, "Viscous Sublayer and Adjacent Wall Region in Turbulent Pipe Flow," Phys. Fluids, vol. 10, no. 9, p. 1880, 1967.

[24] K. E. Willcox and J. Peraire, "Balanced model reduction via the proper orthogonal decomposition.," AIAA J, vol. 40, no. 11 SRC-GoogleScholar FG-0, pp. 2323-2330, 2002.

[25] A. Robert, "A stable numerical integration scheme for the primitive meteorological equations," Atmosphere-Ocean, vol. 19, no. 1, pp. 35-46, 1981.

[26] A. J. Chorin, "A numerical method for solving incompressible viscous flow problems," J. Comput. Phys., vol. 2, no. 1, pp. 12-26, 1967.

[27] Python Software Foundation., "Python Language Reference, version 2.7." .

[28] D. T. Mullen, M. M. Keane, M. Geron, and R. F. D. Monaghan, "Automatic extraction of reduced-order models from CFD simulations for building energy modelling," Energy Build., vol. 99, pp. 313-326, Jul. 2015.

[29] H. Rosten, D. Spalding, and D. Tatchell, "PHOENICS: a general-purpose program for fluid-flow, heat transfer and chemical-reaction processes.," CHAM, 1983.

[30] T. Marzullo, S. Yousefian, M. M. Keane, M. Geron, and R. F. D. Monaghan, "A Comparative Study of Computational Algorithms used in the Automatic Generation of Reduced-Order Models from CFD Simulations," in 3rd Building Simulation Applications conference proceedings, 2017.

[31] "SINDA/FLUINT." [Online]. Available: www.crtech.com/sinda.html. [Accessed: 20Jul-2016].

[32] H. Li, D. Yu, and J. E. Braun, "A Review of Virtual Sensing Technology and Application in Building Systems," HVAC\&R Res., vol. 9669, pp. 37-41, 2011.

[33] H. Tan and L. Dexter, "Improving the accuracy of sensors in building automation systems," in Proceedings of the 16th IFAC World Congress, 2005.

[34] P. Fritzson and V. Engelson, "Modelica-A unified object-oriented language for system modeling and simulation," ECOOP'98-Object-Oriented Program., vol. 1445, pp. 6790, 1998. 
Credit Author Statement

Thibault Marzullo : Conceptualization, Methodology, Software, Validation, Formal Analysis, Investigation, Data Curation, Writing - Original Draft, Visualization ; Marco Geron :

Conceptualization, Methodology, Validation, Resources, Writing - Review \& Editing, Supervision ; Marcus Keane : Conceptualization, Resources, Writing - Review \& Editing, Supervision, Project Administration, Funding Acquisition ; Rory Monaghan : Conceptualization, Methodology,

Resources, Writing - Review \& Editing, Supervision, Project Administration, Funding Acquisition 


\section{Statement of conflict of interest}

We wish to confirm that there are no known conflicts of interest associated with this publication and there has been no significant financial support for this work that could have influenced its outcome. We confirm that the manuscript has been read and approved by all named authors and that there are no other persons who satisfied the criteria for authorship but are not listed. We further confirm that the order of authors listed in the manuscript has been approved by all of us.

We confirm that we have given due consideration to the protection of intellectual property associated with this work and that there are no impediments to publication, including the timing of publication, with respect to intellectual property. In so doing we confirm that we have followed the regulations of our institutions concerning intellectual property.

We understand that the Corresponding Author is the sole contact for the Editorial process (Including Editorial Manager and direct communications with the office). He/she is responsible for communicating with the other authors about progress, submissions of revisions and final approval of proofs. We confirm that we have provided a current, correct email address which is accessible by the Corresponding Author and which has been configured to accept email from energy@elsevier.com.

Signed by all authors as follows:

Thibault Marzullo (28/11/2018)

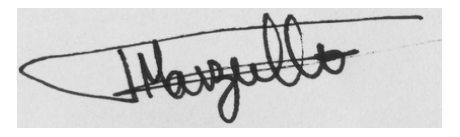

Marco Geron (28/11/2018)

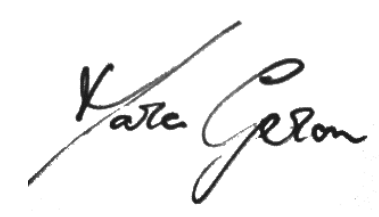

$$
\text { Meras Keane }
$$

Marcus M. Keane (28/11/2018)

Rory F. D. Monaghan (28/11/2018)

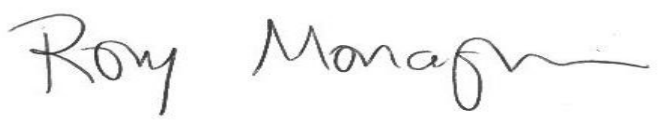

